Western University Scholarship@Western

Digitized Theses

Digitized Special Collections

1971

\title{
Visual Short-term Memory And Aging
}

Jan Kazimierz Adamowicz

Follow this and additional works at: https://ir.lib.uwo.ca/digitizedtheses

\section{Recommended Citation}

Adamowicz, Jan Kazimierz, "Visual Short-term Memory And Aging" (1971). Digitized Theses. 555.

https://ir.lib.uwo.ca/digitizedtheses/555

This Dissertation is brought to you for free and open access by the Digitized Special Collections at Scholarship@Western. It has been accepted for inclusion in Digitized Theses by an authorized administrator of Scholarship@Western. For more information, please contact tadam@uwo.ca,

wlswadmin@uwo.ca. 
The author of this thesis has granted The University of Western Ontario a non-exclusive license to reproduce and distribute copies of this thesis to users of Western Libraries. Copyright remains with the author.

Electronic theses and dissertations available in The University of Western Ontario's institutional repository (Scholarship@Western) are solely for the purpose of private study and research. They may not be copied or reproduced, except as permitted by copyright laws, without written authority of the copyright owner. Any commercial use or publication is strictly prohibited.

The original copyright license attesting to these terms and signed by the author of this thesis may be found in the original print version of the thesis, held by Western Libraries.

The thesis approval page signed by the examining committee may also be found in the original print version of the thesis held in Western Libraries.

Please contact Western Libraries for further information:

E-mail: libadmin@uwo.ca

Telephone: (519) 661-2111 Ext. 84796

Web site: http://www.lib.uwo.ca/ 


\title{
VISUAL SHORT-TERM MEMORY \\ AND AGING
}

\author{
by \\ Jan Kazimierz Adamowicz \\ Department of Psychology
}

\begin{abstract}
Submitted in partial fulfillment
of the requirements for the degree of

Doctor of Philosophy
\end{abstract}

Faculty of Graduate Studies

The University of Western Ontario

London, Canada

August, 1971

C Jan K. Adamowicz 1971 


\begin{abstract}
Short-term memory functioning of young and older* adults was studied in two experiments in which recall and recognition tasks were used. The stimuli consisted of visual patterns containing either 6.1 or 13.7 bits of information. In the first experiment, the independent variables included age, sex, delay and task complexity. The dependent variables consisted of recall and recognition performance scores and recall and recognition viewing times (self-paced). Analysis of results indicated that: a) older people had longer viewing times for recognition tasks b) older people remembered as well as the young in recall but not in recognition tasks c) viewing time interacted in a complex manner with other variables, i.e.,sex, complexity, and delay. In the second experiment, viewing time was paced and consisted of 3,6, or 12 seconds, the other variables remaining the same as in the first experiment. Short-term memory performance was the dependent variable. Analys is of the results indicated that: a) older people remembered less than the young in recall tasks, b) older people remembered less than the young in recognition tasks, c) complex interactions took place between short-term memory performance and sex, delay and viewing time. The results were interpreted as suggesting that: a)older adults display a slowing in information processing at the registration phase, b) older adults are more susceptible to interference during the
\end{abstract}

* See Appendix I for a definition of "older". 
storage phase, c) older adults do not exhibit a specific retrieval deficit.

Additional data included measures of imaging ability (QMI), verbal intelligence (QWT), visual discrimination and use of strategies (post-experimental inquiry). Analysis of the results did not suggest any reliable relationships between these variables and short-term memory performance. 


\section{ACKNOWLEDGMENTS}

The author wishes to acknowledge and express his appreciation to Dr. Morris M. Schnore for providing helpful suggestions and advice during all stages of this thesis. Appreciation is also expressed to the members of the advisory committee consisting of Drs. A. Bartoshuk, R.C. Gardner, W.J. McClelland and T. Siess. Special thanks are due to Dr. R.C. Gardner for helpful statistical advice.

The author also wishes to express his deep gratitude to the staff of the St. Thomas Psychiatric Hospital in St. Thomas, Ontario, for the cooperation and assistance which they provided toward the collection of the data for this study, and especially Miss Beatrix Horn, the Acting Chief Psychologist and Dr. K.M. McGregor, the Superintendent. 
TABLE OF CONTENTS

Page

Certificate of examination ............. i i ABSTRACT .............................

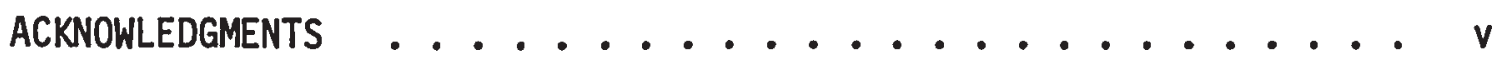

LIST OF TABLES ..................................

LIST OF FIGURES .................. ix

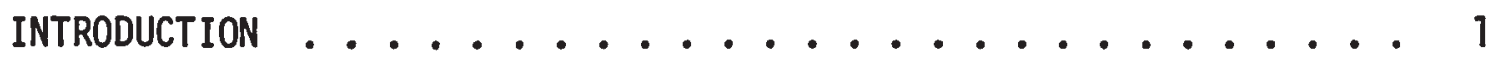

Registration ............. 2

Storage ............... 6

Retrievai ................... 8

Visual Short-term Memory and Aging ....... 13

Present Research ............ 17

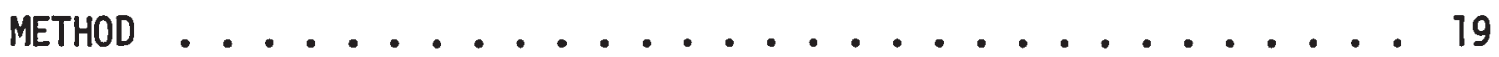

Materials and Apparatus ........... 19

Subjects .............. 23

Procedure ............... 25

Design ..................... 26

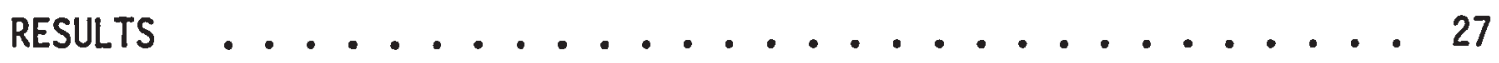

Experiment I ............. 27

Experiment II ............... 30

Summary of the Results .......... 37

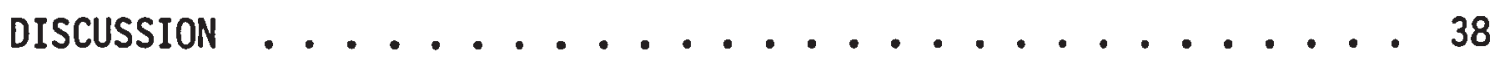

Registration ............. 38

Storage ............... . . 42

Retrieva .............. 43

Related Variables ............ 45

Summary and Conclusions .......... . 47

SUGGESTIONS FOR FUTURE RESEARCH .............. 48 


\section{Page}

REFERENCES . . . . . . . . . . . . . . 49

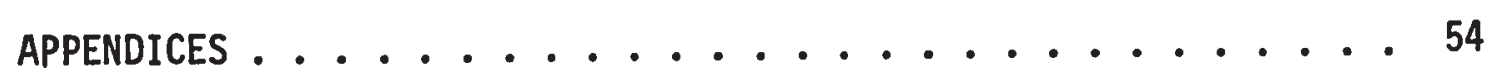

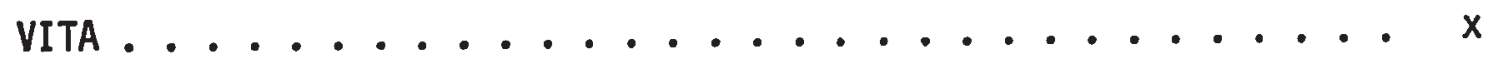




\section{LIST OF TABLES}

Page

TABLE

1 Demographic data for Experiments I and II . . . . . 24

2 (a) Mean self-paced viewing times as a function of delay, sex and complexity (Experiment I) ....... 29

2 (b) Mean self-paced viewing times as a function of age, delay, sex and complexity (Experiment I) ..... 29

3 (a) Mean recognition memory scores as a function of sex and viewing time (Experiment II) ....... 32

3 (b) Mean recognition memory scores as a function of age and delay (Experiment II) ............ 32

4 Mean recognition memory scores as a function of age, complexity, delay and viewing time (Experiment II) . . 33

5 Mean recognition memory scores as a function of age, sex, complexity, delay and viewing time

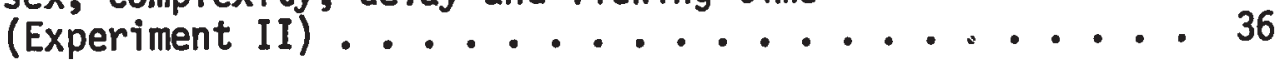




\section{LIST OF FIGURES}

Page

FIGURE

1 Example of a 6.1 bit stimulus pattern with 6 response choices ................. 21

2 Example of a 13.7 bit stimulus pattern with 6 response choices .............. 22

3

Mean recall memory scores as a function of age and viewing time (Experiment II) ........ 31

4

Mean recognition memory scores as a function of age, complexity, delay and viewing time (Experiment II) .................. 34 
INTRODUCTION

There has been a dramatic upsurge in research in the last twenty years on the effects of aging. This research has been directed at delineating precisely the biological and psychological changes accompanying old age. While the overt biological concomitants of aging are relatively consistent from person to person and are relatively easy to observe, the cognitive changes accompanying old age have been more elusive and more variable. As a result, there are a number of controversies in the literature related to disparate and inconsistent research findings. Generally speaking, researchers report a gradual decline in cognitive functioning after a peak at about age 20 (Welford, 1958). Welford (1958) hypothesized that performance deteriorates with aging because of organic injuries to the CNS but improves as a result of experience. In analyzing the learning process, Welford subdivided it into a number of stages: 1) perception, 2) short-term memory (STM), 3) development of a durable trace, 4) endurance of the trace, 5) retrieval of the stored material, and 6) use of the recovered data. He postulated that STM deficits play a significant role in age related deterioration of the learning process. Research evidence supports this notion. In a review of the literature, Inglis (1965) cited numerous studies suggesting that STM deficits of the elderly are frequently responsible for their less efficient cognitive functioning. The processes underlying STM functioning can be separated into three 
phases: registration, storage, and retrieval. The disturbance of any of these stages might lead to memory impairment. Hypotheses explaining age related STM deficits have been linked to each one of these phases. It has been postulated that the elderly exhibit poor STM because of inadequate encoding of stimulus materials during the registration phase. This inefficiency has been attributed both to poor use of strategies and a slowing of information processing by the CNS. In addition, it has been hypothesized that encoding at the registration phase is susceptible to stimulus erasure if frequency of stimulus presentation is high. It has been proposed that during the storage phase, the elderly exhibit greater memory trace decay than the young as well as a greater susceptibility to disruption of memory traces by interfering materials. Concerning the retrieval phase, it has been hypothesized that the elderly display a specific deficit in retrieving stored information. Also, it has been proposed that the elderly need more time than the young to produce responses. Empirical evidence in regard to these hypotheses will be evaluated below, beginning with the registration phase.

\section{REGISTRATION}

Encoding slowdown. Welford $(1958,1965)$ noted that a general decrease in information handling capacity of the sensory-motor system seems to be a reliable concomitant of advancing age. This finding suggests that the elderly should be slower than the young in processing incoming information. This hypothesis is supported by the following research findings. Wallace (1956) showed parts of visual displays serially so that $\underline{S} s$ had to integrate the material in order to identify the total display. Her stimulus materials consisted of simple and complex 
geometrical figures, silhouettes, and pictorial line drawings. While

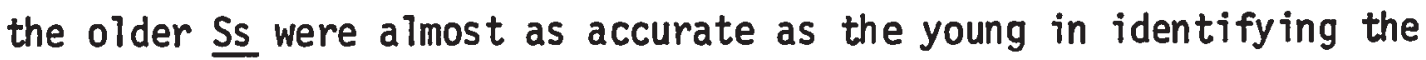
first two sets of stimuli, their performance deteriorated for the last two sets and especially for the line drawings. She attributed this difference in performance to the increasing information processing demands with increasing stimulus complexity. In another experiment, Wallace (1956) used line drawings only and $\underline{S s}$ in their twenties, thirties, forties, fifties, and sixties. A marked decline in performance occurred when going from the forties to the sixties group. 01der Ss took about 15 to 20 times longer than did the younger Ss to identify the stimulus patterns. This slowness was especially apparent for the more complex patterns, the explanation for this being that more information processing is required for these and that the elderly are slower than the young in that regard. This complicates the issue further in that information which is not processed and encoded, must nevertheless be retained in a perceptual STM system which then quickly becomes overloaded. Wallace (1956) interpreted her findings as indicative of: a) a slowdown in the identifying process with age, b) poorer STM functioning with age. The hypothes is of an age related slowdown in the identifying process, is further supported by Eriksen, Haml in and Breitmeyer (1970). Eriksen et al (1970) found that older adults required longer exposure durations in order to identify forms (Landolt C) even when equated with younger adults on standard measures of visual acuity. In analyzing the results, they concluded that while sensory organ impairment contributed to some extent to decreasing performance with age, the main decrement probably reflected a slowing 
of information processing with in the CNS. Suci, Davidoff and Surwillo (1960) investigated the effect of the amount of information contained by stimuli on reaction times of superior young and old Ss. They found that reaction time(RT) increased as a linear function of the amount of information contained by the stimulus pattern for both young and old Ss but the regression line for old people had larger intercept and slope values, that is, the older poeple were slower than the young and this decrease in speed increased directly with increasing information content. The results suggest that older $\underline{\text { Ss }}$ were slower at processing the incoming information. With increasing stimulus complexity, the slowdown became especially apparent.

Inadequate encoding methods. Another important variable related to the registration phase is the utilization of encoding strategies. Research findings suggest that STM coding methods are age related such that old people use primarily verbal mediators (Hulicka, 1965), whereas young Ss use primarity imaginal mediators (Paivio, 1965). Various researchers have reported that use of imaginal coding methods leads to improved recall performance with young adults (Sheehan, 1966a, 1966b; Williams and Fish, 1965; Paivio, 1971). Less clear-cut findings have also been reported. Canestrari (1968) investigated the relationship between age, use of strategies and type of strategy used. His $\underline{\text { Ss were }}$ provided with either verbal or imaginal mediators in a paired-associate (PA) learning task. Results showed that the young performed better than the elderly in all conditions but the old improved significantly more than the young in going from the control condition (no strategies provided) to the experimental condition (strategies provided). Canestrari did not 
observe any difference between imaginal and verbal mediators for either of the age groups. The results suggest that the elderly are hampered by inadequate usage of strategies; however, even when this deficit is overcome, age related STM decrements still occur.

Erasure. According to Welford's (1958) analys is of the learning process, if stimuli are presented in rapid succession, then the establishment of a durable trace will be difficult and memory will suffer. In effect, it is not the length of time taken to respond that is important but the overall frequency of stimulus presentation. This hypothes is was supported by Arenberg (1965). In his study, young and old Ss learned lists of paired-associates using short and long anticipation intervals. Interspersed throughout were self-paced trials where $\underline{S s}$ could take as long as they wanted to respond. Analys is of errors showed that both

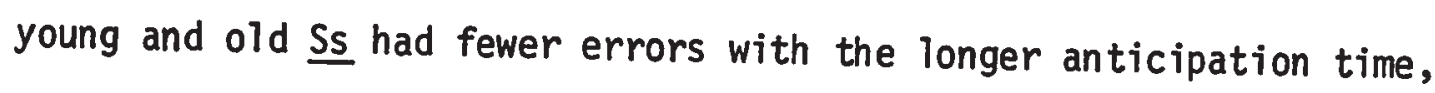
regardless of the pacing condition. This suggests that it is not just response time, but the susceptibility to a kind of an erasure phenomenon as suggested by Welford that leads to poorer performance in the elderly. Canestrari (1968) presented some further evidence supporting the erasure hypothesis. He used $152 \underline{\text { Ss }}$ in a PA verbal learning experiment. Each stimulus was presented on the screen for one second but the inter-pair delay was either $0, \frac{2}{2}$, or 5 seconds. Each 1 ist was presented five times. Subsequently, the Ss were provided with the stimulus words and were required to recall the response words. No time limit was placed on recal1. The results showed significant age and interval differences as well as an age by interval interaction. While the aged showed an improvement in performance with longer inter-stimulus intervals, 
their performance still did not reach the level achieved by the young. Analys is of intralist intrusion errors showed significant differences suggesting that the poorer performance of the elderly was not a function of interitem interference. In effect, poorer STM performance was related to higher frequency of stimulus presentation for both groups, but especially for the older. Unfortunately, with lower frequency of stimulus presentation, other variables enter into the situation such as the use of strategies and response mobilization and storage.

STORAGE

Broadbent's (1957) dichotic stimulation technique has proven very useful in STM research. It essentially consists of presenting a short series of stimuli simultaneously to both ears. Subjects are required to recall the stimuli presented in one ear, then the stimuli presented to the other ear. Using dichotic stimulation, Inglis and his colleagues (Inglis, 1965; Inglis and Caird, 1963; Inglis and Ankus, 1965) repeatedly found an age related decrement in the second half-set of digits to be recalled but not in the first half-set. They reasoned that the first half-set went directly into a peceptual system whereas the second was held in short-term storage until it could be reproduced. They found that recall of the second half-set deteriorated with increasing age and deteriorated even more with memory impaired aged patients. In addition, this deterioration became more pronounced with increasing length of digit series. Ingl is (1965) interpreted these results as suggesting an increase in memory trace decay during storage as well as an increase in susceptibility 
to interference with advancing age. In a review of the literature, Norman (1970) also concluded that, generally, poor memory performance is due to trace decay, interference and the interaction of these variables. The findings of Inglis (1965), suggest that these variables play increasingly important roles in age related STM deficits. Interference effects, however, interact with aging and memory in a more complex manner than has been suggested by Inglis (K1 ine, 1970; Keevi1-Rogers and Schnore, 1969; Tarpy and Marsha11, 1970, and others). In Kline's (1970) recognition memory study, Ss were presented with single and grouped letters which were then followed by slides containing visual noise. He found that the aged performed at about the same level as the young when the interval between the stimulus and visual noise was about twice as long as that for the young. Shorter intervals led to poorer performance and longer intervals to better performance.

Interpolation of a task between stimulus presentation and recall has two effects on STM: a) it allows memory trace decay to take place by eliminating covert rehearsal, and b) if covert rehearsal does take place, the interpolated task facilitates intrusion errors. The former finding is well established and the latter is supported by Tarpy and Marshal1 (1969) and Tarpy et al.(1969). The effects of interference become greater as the similarity between the original stimuli and interpolated task increases (Gibson, 1941; Bruning and Schappe, 1965).

Using Ss of above average intelligence, Keevil-Rogers and Schnore (1969) found no statistically significant difference between young and old when an interference task was interpolated between 
stimulus presentation and retrieval. Kriauciunas' (1969) results also showed no significant differences between young and old $\underline{\text { s. }}$. In both of the preceding studies, differences were observed but they were not large enough to be of statistical significance. Taub and Walker (1970) found interference effects to be related to the methum of equating young and old $\underline{S s}$ and also to the serial position of the stimuli, the last half being susceptible to interference but not the first. Arenberg (1968) has reported that age related interference effects showed up most prominently with visually presented stimuli and were smaller with a combined visual-aural input. In effect, storage related STM deficits in the elderly seem to be a function of: subject IQ, type of stimuli used, type of interpolated task stimuli used, duration of the delay interval and duration of the interval between stimulus offset and interpolated task onset.

RETRIEVAL

Response mobilization. Eisdorfer, Axelrod and Wilkie (1963) investigated the effects of anticipation period duration on rote verbal learning. They hypothesized that increased duration of the anticipation period would lead to greater gains in learning for the aged in comparison to the young. Their lists consisted of 8 familiar five letter words which were presented on slides for 4,6 , or 8 seconds with inter-word intervals of one second. The method of serial anticipation was used. As predicted, there was an improvement in performance of the elderly in going from short to long anticipation 
periods. The young did not show any such trend even though their performance was superior to that of the old on the whole. Analys is of omission and commission errors suggested that the older group performed better with 8 second anticipation periods, because of increased opportunity to produce responses and not because of increased learning of S-R connections. Their hypothesis was tested in a further experiment where the Ss had 15 trials to learn their lists. Two conditions were compared: condition $A$ in which 4 second anticipation periods were used for all but two trials (trials 8 and 9 where anticipation time of 8 seconds was used) and condition B in which 8 second anticipation periods were used for all but two trials (trials 8 and 9 again, with anticipation time of 4 seconds). The authors reasoned that increased anticipation time during trials 1 to 7 would allow increased learning to take place in condition B. The elderly, therefore, should perform better on trials 8 and 9 of condition $B$ in comparison to trials 8 and 9 of condition A. No differences were observed between the two conditions on trials 8 and 9 and Eisdorder et al. concluded that the salient factor in efficiency of performance was not the increased opportunity to learn $S-R$ connections but the increased opportunity to respond. In an investigation of optimal anticipatory period durations, Eisdorfer (1965) found that performance of the elderly improved monotonically with increasing response intervals, reaching its asymptote at the ten second mark. Thus, it would seem that old people need more time to mobilize their responses. 
Other hypotheses. Short-term memory studies using verbal materials suggest yet another hypothes is to explain age related STM deficits, i.e., the retrieval deficit hypothesis. In a free recall STM experiment, Craik (1968) compared memory performance of young and old adults on four different stimulus lists: digits ( 5 to 10 items per 1 ist), county names ( 5 to 20 items per 1 ist), an imal names ( 5 to 20 items per 1 ist) and unrelated words ( 5 to 20 items per list). Craik reasoned that if the aged exhibit a retrieval deficit, they will be particularly disadvantaged in recalling stimuli without simplifying cues and also those necessitating extensive searching operations. The latter condition would be satisfied if the lists were long and the former if the potential stimulus pool was large. The four stimulus lists used by Craik seem to present a gradient of stimuli with such characteristics. Craik (1968) predicted that the aged would do worse than the young with increased list length and that this decrement would increase with vocabulary size. Craik found that indeed, there was an age by list length interaction such that with longer lists the young recalled more than the old. However, Craik also observed that neither an age by list type interaction, nor an age by list length by 1 ist type interaction took place. These findings provide only fragmentary evidence for the retrieval deficit hypothes is as STM performance of the elderly did not decrease significantly with an increase in vocabulary size nor did it decrease significantly with a combined increase in list length and vocabulary size. Schonfield and Robertson (1966) also proposed an age related retrieval deficit based 
on a different line of evidence. According to the two-process theory of memory, recall memory is a measure of both storage and retrieval whereas recognition memory is mainly a measure of storage since in the latter the subject is required to match existing memory traces to presented alternatives without any active retrieval (Noman, 1970). Schonfield and Robertson (1966) examined STM of young and old Ss using recall and recognition tasks. Their stimulus materials consisted of 48 mono and di-syllabic nouns and adjectives. These were presented

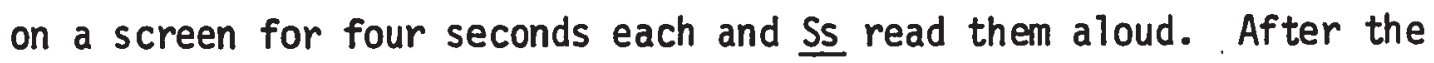
last word (in a list of 24 ) was presented, Ss had to verbalize all the words that they could remember in the recall condition. In the recognition mode, after the stimulus words were given, $\underline{\text { S }}$ were presented with groups of 5 words, one of which was on the original list. Their task was to underline the previously shown word. Subjects were chosen from each decade beginning with 20-29 and ending with 60+. Younger $\underline{\text { Ss }}$ were university students whereas the older ones were either connected with the university or were professional people. The authors reported a linear decline with age in the number of words recalled but no age related differences for the recognition task. The number of words recalled ranged from 7.50 to 13.78 whereas the number of words recognized ranged from 19.48 to 20.09 (out of 24). Schonfield and Robertson (1966) concluded that the aged seem to have a special difficulty at the retrieval phase, since in the condition presumably requiring only storage but no retrieval (recognition task), there was no memory deterioration with increasing age. The study is not beyond criticism, however. The recognition task used by the authors was 


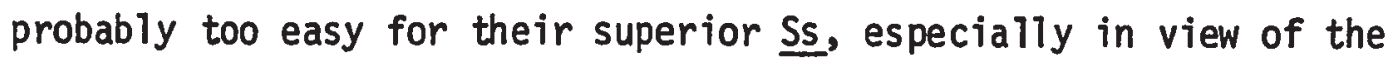
fact that recognition memory is generally better than recall memory (Postman et al., 1948; Bruce and Cofer, 1965). Furthermore, ceiling

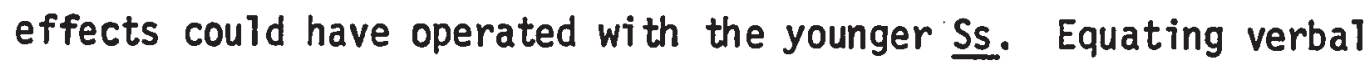
recall and recognition tasks on difficulty is almost impossible and was not even attempted here. An even more serious criticism has been raised by McNulty and Caird (1966). McNulty (1966) presented some evidence supporting a partial learning model for recognition memory. The model states that either complete initial learning of stimuli and partial recall or partial initial learning of stimuli and complete recall will lead to correct recognition memory but incorrect recall performance. McNulty (1966) found that when both structural and associative type partial learning was removed from a nonsense syllable STM experiment, all retrieval differences disappeared between recall and recognition measures. On the basis of those findings and some additional data, McNulty and Caird (1966) suggested that the focus of STM deterioration with age rests in registration and/or storage phases and not the retrieval phase as Schonfield suggested. Schonfield (1967) defended his position and presented some further data using patients suffering from organic psychoses. The patients performed poorly on recall tasks but much better on recognition tasks. However, Caird (i965) found 75 year old psychiatric patients to do equally badly on both recall and recognition tasks (in comparison to a control group). According to Attneave (1959), some recognition tasks can be varied in difficulty by: a) increasing the similarity of distractors to the correct alternative, and b) increasing stimulus complexity. Since 
verbal stimuli are described by both distinctive semantic and acoustic cues, it is very difficult if not impossible to manipulate their recognition difficulty. Thus, they are ill-suited for recognition STM experiments. Visual patterns, on the other hand are readily adaptable to either or both of these methods ofchanging task complexity. Johnson (1966) using the visual stimuli developed by Schnore and Partington (1967), examined recognition memory of young and older $\underline{\text { Ss }}$ as a function of information content of stimuli (high and low). Difficulty of recognition tasks was varied by making al ternatives either distinct or similar to the test pattern. Johnson found that recognition scores for difficult tasks were significantly poorer for the old Ss than for the young but no age effects were found with the easier recognition tasks. Using patterns similar to those used by Johnson, Adamowicz (1971) compared visual STM of alcoholics and normals. Analys is of the results revealed recognition but no recall differences between normals and alcoholics matched for age. The results suggested that poorer STM performance of the alcoholics was associated not with retrieval difficulties but with increased interference effects as provided by the various alternatives of the answer slide.

VISUAL SHORT-TERM MEMORY AND AGING

Most of the studies reviewed above investigated the effects of aging on STM of visually presented verbal stimuli. The study of speed of registration phase processes using verbal stimuli is questionable, however, as verbal symbol identification is extremely fast (Norman, 1970). The appropriateness of postulating a retrieval deficit on the basis of recognition performance with verbal stimuli 
is also questionable. Verbal stimuli do not lend themselves easily to variation in difficulty levels and are even less amenable to being equated with recall tasks. The few aging and STM studies where visual forms have been used will be examined below.

Research with visually presented non-verbal stimuli has shown a decl ine in STM with age. Since the Bender Visual-Motor Gestalt Test was first published in 1938, it has received extensive cl inical use, frequently as a test of recall (Billingslea, 1963). Tolor and Schulberg (1963) have presented some sketchy evidence suggesting that recall of the Bender figures deteriorates with age. There are problems with this test, however. It was designed to detect organicity yet its reliability and validity are still in question (Blakemore, 1965; Hannah, 1958; Peek and Storms, 1958). The geometric stimulus figures have been arbitrarily chosen and performance evaluation is laborious and imprecise. Few attempts have been made to delineate the relationship between STM performance and empirical stimulus characteristics. Goodstein, Spielberger, Williams and Dahlstrom (1955) examined recall of the Bender figures in relation to serial position and difficulty of the stimuli. They found that recall decreased with increases in figure difficulty and increased with practice effects, i.e., it was better with figures presented last. Critical stimulus characteristics of the Bender-Gestalt, such as for example, indices of stimulus complexity, have not as yet been determined. Bender's test shares these problems with other tests such as Graham-Kendall's Memory-for-Designs Test (MFD) (1960) and Benton's Visual Retention Test (1955). Kendall (1962) presented evidence 
on age changes in STM with regard to the MFD test. She found only a slight deterioration in performance up to age 60 but a rapid one thereafter. Benton (1955) stated that maximum performance on his test reaches a plateau at about age 15 and does not decrease until the forties, when there is a slight decrease which is followed by a further slight decrease in the fifties. In a critique of Benton's test, Hanawalt (1959) stressed that the test does not separate perceptualmotor and memory functions as the subject must reproduce the figures with accuracy. Thus, drawing skill enters into the performance. The foregoing studies are subject to a number of criticisms. The stimuli for the tests have been arbitrarily derived and have no objective scoring criteria. In all cases, confounding of perception or visual-motor coordination with memory is likely. In addition, little attempt has been made to analyze the processes underlying task performance and to pinpoint the causes of declining recall. Another attack on the problem has been made recently, however, with the help of information theory.

Following the lead of Attneave (1955, 1959), Schnore and Partington (1967) developed a perceptual memory for patterns test. In an empirical analysis of the properties of this test, Schnore and Partington (1967) used four levels of stimulus complexity: a) 2.6 bits* and $84 \%$ redundancy, b) 6.1 bits and $62 \%$ redundancy, c) 9.9 bits and $38 \%$ redundancy, and d) 13.7 bits and 15\% redundancy. Their patterns were presented to the $\underline{S}$ for 2.5 seconds and response intervals

* For a discussior of "bits" refer to p.19 
consisted of 10 seconds. Subjects were required to reproduce the patterns immediately after slide offset. They did so by indicating the location of black cells on response sheets containing empty four by four matrices. Schnore and Partington (1967) found memory scores to be essentially linearly related to the amount of information in the design so that while there were very few errors for 2.6 and 6.1 bit designs, there was a reliable increase in error scores for designs containing 9.9 and 13.7 bits of information. They also observed a significant positive correlation between age and total number of recall errors but no sex effects.

Schnore (1969) has reported a number of studies using the patterns developed by Schnore and Partington (1967). Using psychiatric patients as $\underline{\text { Ss, }}$, Schnore (1969) observed reliable visual STM decrements as a function of age. In addition, he noted that performance on the visual memory task correlated significantly with measures of general memory functioning even when differences in visual-spatial ability were controlled. In one of his experiments, Schnore found age related differences in visual STM after his Ss were equated on the WAIS vocabulary and block design subtests. In another, he observed that aged patients with poor scores on a memory rating scale recalled fewer of the patterns than did their counterparts with good memory scores. Schnore (1969) hypothesized that the age related decrement in visual STM is due to faster memory trace decay. Although he did not find any recall differences between 4 and 8 second delay conditions in one of the studies, a comparison of the results obtained with delay with those without a delay, indicated that the age difference in recall 
was greater with response delay. Some of Schnore's (1969) data suggest, however, that the aged may have encoding difficulties because a dramatic increase in errors was obtained when stimulus viewing time was reduced to 1.5 seconds.

\section{PRESENT RESEARCH}

Short-term memory studies with verbal stimuli, suggest that older adults exhibit little slowdown in encoding speed during the registration phase. This conclusion, however, may not apply to other visual stimuli. Some studies of perceptual perforinance (Wallace, 1956; Suci et al., 1960) do suggest that the elderly exhibit a slowing in information processing during the registration phase. Studies of STM and aging using visual patterns (Johnson, 1966; Schnore, 1969) suggest that age related STM decrements are related to the registration phase. One of the purposes of this investigation was to examine visual STM functioning of young and older adults in relation to paced (short, intermediate and long) and self-paced registration time intervals using objectively derived, non-verbal, visual patterns. The findings discussed above lead to differential performance predictions. If there is a slowing of information processing at the registration phase, then older $\underline{S s}$ would be expected to have longer self-paced viewing times and perform worse than the young with paced registration periods of short duration. If there is no slowing in information processing at the registration phase, no performance differences between young and older $\underline{S}$ wouid be expected.

An age related retrieval deficit hypothesis has been proposed by Schonfield and Robertson (1966) and Craik (1968). These authors 
suggested that poor STM performance of the aged is probably attributable to a special difficulty in retrieving items from storage. Both the Craik and Schonfield and Robertson studies have been criticized for several reasons. For example, comparisons of performance on recall and recognition tasks using verbal stimuli is a methodologically questionable procedure. In a test of the retrieval deficit hypothesis, Johnson (1966) found age related differences in recognition memory. One of the purposes of this investigation was to replicate and extend the Johnson study.

Hulicka and her colleagues have repeatedly found that mediational variables play an important role in age related STM deficits. Hulicka (1965) reported that the elderly used fewer mediators than the young. In addition, older $\underline{\text { Ss }}$ used more verbal and fewer imaginal mediators whereas the reverse was true for young Ss. Paivio (1965) independently found that young $\underline{\text { SS }}$ used predominantly imaginal mediators. Paivio et al. (1968) reported that young adults using imaginal mediators displayed superior STM performance in comparison to verbal mediator users. These results suggest that imagery plays an important role in STM. Therefore, it would be expected that Ss obtaining high scores on a scale of imagery would display superior recall in comparison to low scorers. Furthermore, according to Hul icka's findings, it would be expected that the use of imaginal mediators would decrease with age and this decrease would hamper STM performance of the older $\underline{\text { S }}$. Canestrari's (1968) findings, however, do not support the foregoing hypotheses; he found no recall differences as a function of type of strategy used for both young arid old adults. 
METHOD

Materials and Apparatus

The stimulus patterns used in this study contained 6.1 and 13.7 bits of information and were designated as simple (S) and complex (C) respectively. A modification of Attneave's method of derivation was used. Attneave (1959) described an approach for quantifying visual patterns based on information theory. He defined information (H) as the reduction or removal of uncertainty such that $H=\log _{2} m$ where $(m)$ refers to the number of possible alternatives in any given situation. Thus, rolling a die involves $\log _{2} 6=2.58$ bits of information. When all the alternatives are equiprobable, $\mathrm{H}$ is at a maximum. Redundancy (C) complements uncertainty $(R)$ so that $C+R=1$ and $R=\frac{H \text { (obtained) }}{H(\text { maximum) }}$ In effect, if a set of events has no constraints and all outcomes are equally likely, then maximum uncertainty will result, i.e., $R=1 / 1=1$. Using the principles described above, Schnore and Partington (1967) developed a perceptual memory for patterns test. They used $4 \times 4$ square matrices with the restriction that half of the 16 cells are black and half are white. If no restrictions are imposed on such a matrix, the maximum amount of information that it may contain is 16 bits. With the above restriction, the total number of possible patterns is $16 !=12,870$ and $H=\log _{2} 12,870=13.7$ bits. The redundancy $(C)$ of such a matrix equals $(1-R)$ where $C=1-\frac{13.7}{16}=15 \%$. To vary stimulus complexity, 
redundancy and information content are manipulated. For example, if only one half of the matrix is randomly determined and the other half is a mirror image of the first one, the matrix becomes $62 \%$ redundant $\left(C=1-\frac{6.1}{16}=62 \%\right)$ and contains 6.1 bits of information $\left(H=\log _{2}\right.$ $\left.\frac{8 !}{4 ! 4 !}=\log _{2} 70=6.1\right)$. It should be noted that the stimuli used in the present study are easily quantifiable using information theory. However, these patterns as well as the dot patterns used by Attneave (1955), represent only a small fraction of the visual forms that have been devised by researchers (Michels and Zusen, 1965). Unfortunately, the psychophysics of visual form is still in its early stages of development and considerably more research will have to be done before a broad range of standardized stimulus materials becomes available (Brown and Owens, 1967).

In the visual discrimination as well as the recognition tasks, Ss had 6 stimuli to choose from in responding, namely the correct pattern plus 5 distractors. For 6.1 bit patterns, the 5 distractors were derived as follows: a) a 90 degree rotation from the test pattern, b) a 180 degree rotation, c) moving 2 squares to make the pattern more symmetrical, d) moving 2 squares to make the pattern less symmetrical, e) adding 2 squares to make the pattern more symmetrical (see Figure 1). Identical procedure was used to derive 13.7 bit designs except that whenever a black square was moved or added, 1 square was used instead of 2 (see Figure 2).

All test patterns and recognition task response choices were presented on slides. Whereas the visual discrimination task slides contained 7 patterns each and the recognition response slides contained 

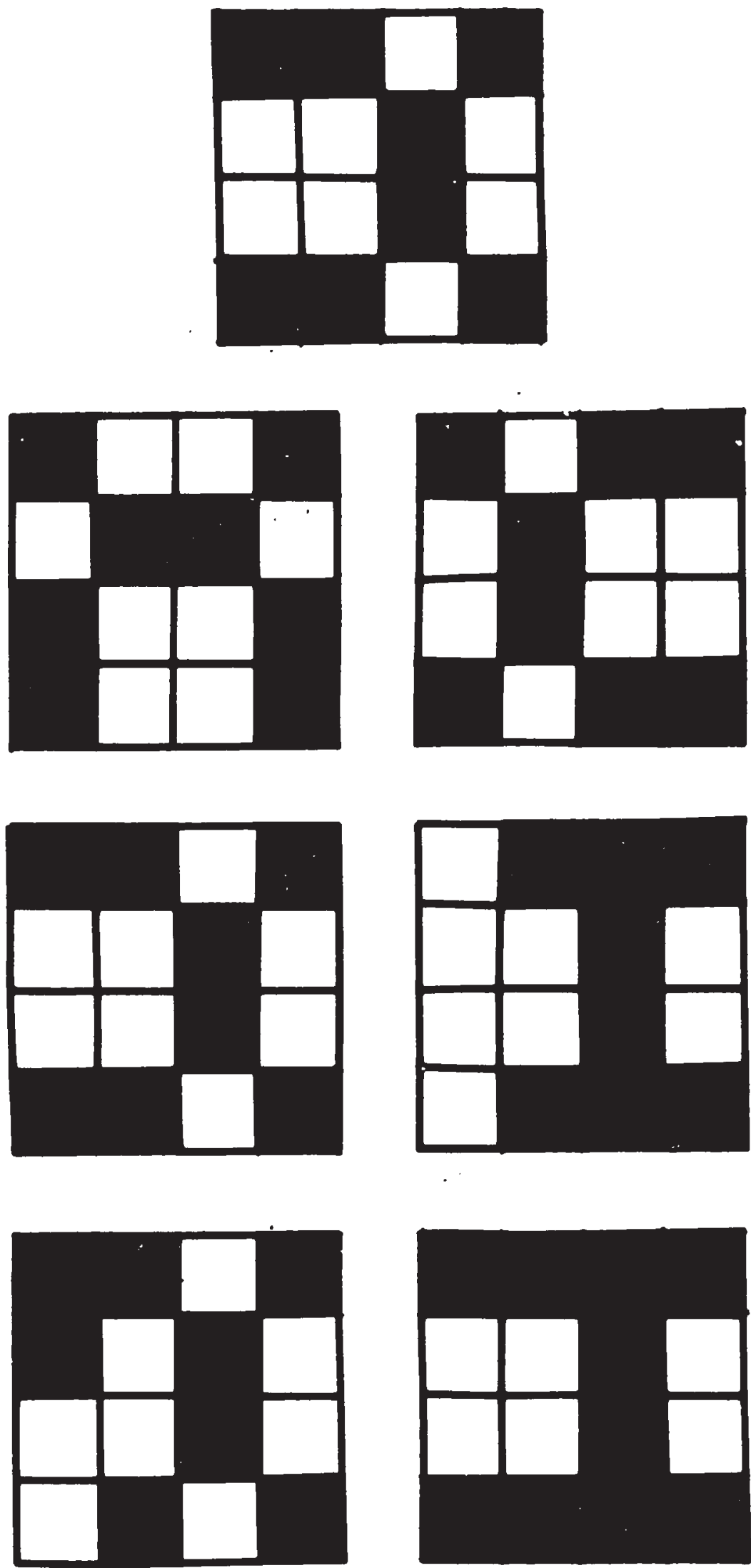

Figure I. An example of a 6.1 bit stimulus pattern with 5 distractors. 

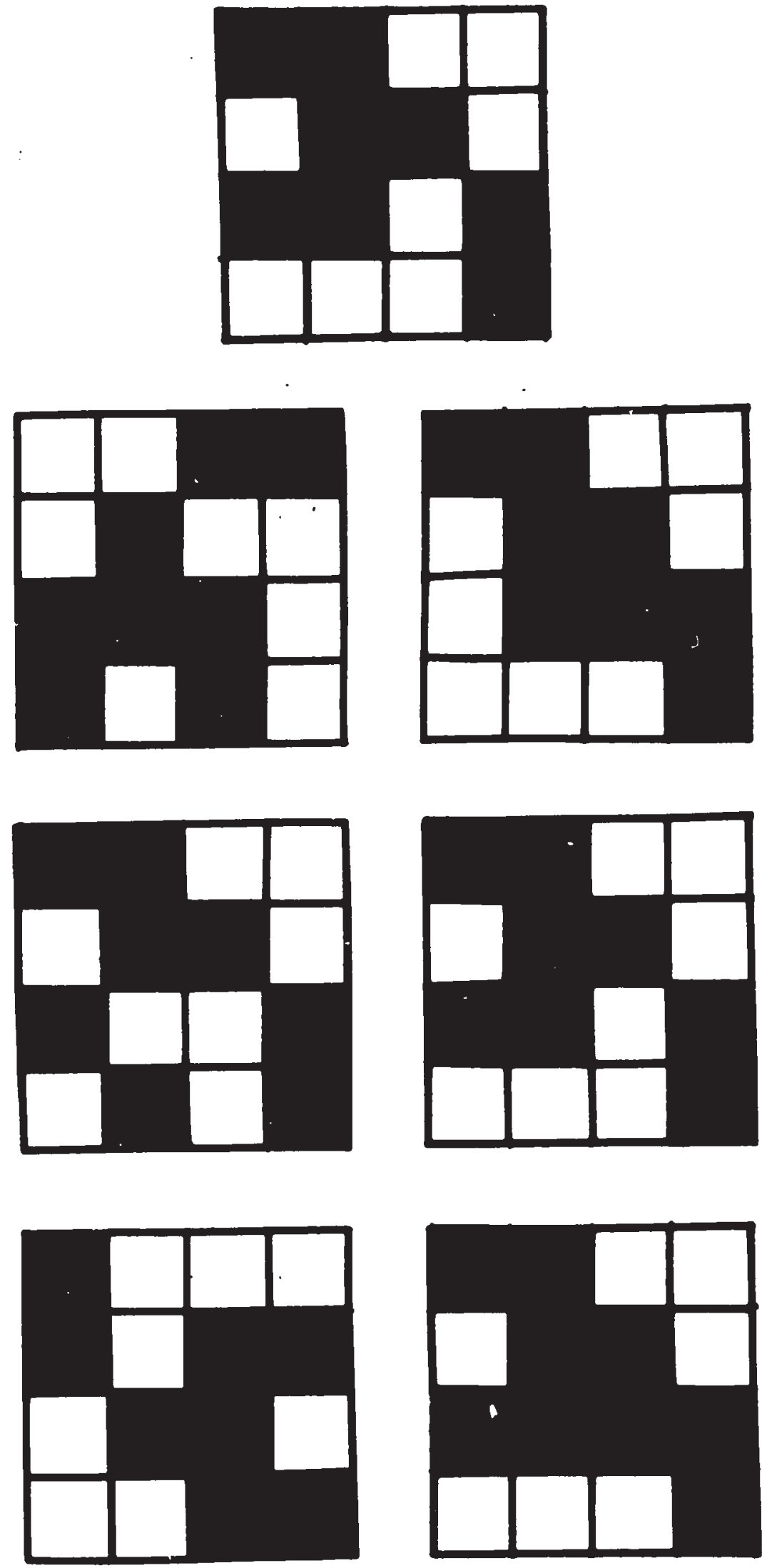

Figure 2. An example of a 13.7 bit stimulus pattern with 5 distractors. 
6 patterns each, the remainder of the slides contained single patterns. Altogether, there were 67 slides: 7 visual discrimination task patterns, 20 simple patterns, 20 complex patterns and 20 recognition task response patterns.

Several questionnaires were used: the Quick Mental Imagery Scale (QMI) (Sheehan, 1965a), the Quick word Test (QWT), and a short postexperimental questionnaire (Experiment II only, see Appendix VIII). QMI assesses imaging ability and QWT is an index of verbal IQ. Sheehan (1966a and b) provides normative data on the QMI scale. The postexperimental questionnaire was designed to determine if $\underline{S} s$ used some method in coding the stimuli. The purpose of the forementioned visual discrimination task was to obtain a measure of $\underline{S} s^{\prime}$ visual acuity.

The slides were presented by a Kodak Carousel 850 slide projector coupled with a Hunter timer and a Sanyo cassette tape recorder. Task presentation was almost completely automated by use of several electronic relays. Self-paced viewing time was measured by a Haydon Switch and Instrument Co. electric clock. A Kodak $6^{\prime}$ by $9^{\prime}$ slide screen was used.

\section{Subjects}

The Ss were 96 employees of a psychiatric hospital who volunteered for the experiment and were paid $\$ 2.00$ for their participation. Most of the $\underline{S} s$ worked as attendants or nurses' aids. Twenty-four $\underline{S} s$ were used in Experiment I and 72 in Experiment II. Table 1 gives a breakdown of $\underline{S}^{\prime}$ age, QMI, QWT and visual discrimination task scores for each group (Experiments I and II). 
Table 1.

Age, visual discrimination, QMI and QWT values for Ss used in Experiment I (24 Ss) and II $(72 \bar{S}$ ). Means and standard devíations are given.

\begin{tabular}{|c|c|c|c|c|c|c|c|c|c|}
\hline & \multicolumn{4}{|c|}{ Young } & \multicolumn{4}{|c|}{ 01der } \\
\hline & & \multicolumn{2}{|c|}{ Male } & \multicolumn{2}{|c|}{ Fema le } & \multicolumn{2}{|c|}{ Male } & \multicolumn{2}{|c|}{ Female } \\
\hline & & $\bar{x}$ & sd & $\bar{x}$ & sd & $\bar{x}$ & sd & $\bar{x}$ & sd \\
\hline \multirow{4}{*}{ Exp. I } & Age & 21.17 & 1.46 & 20.17 & 1.77 & 57.00 & 5.91 & 56.50 & 3.73 \\
\hline & Discrim. & 6.50 & .50 & 6.50 & .50 & 6.83 & .37 & 6.67 & .47 \\
\hline & QMII & 90.83 & 22.87 & 84.83 & 30.76 & 92.33 & 20.31 & 77.17 & 24.21 \\
\hline & QWT & 75.00 & 7.37 & 76.17 & 10.05 & 81.50 & 9.52 & 84.30 & 8.63 \\
\hline \multirow{4}{*}{ Exp. II } & Age & 20.83 & 1.80 & 21.56 & 1.86 & 55.00 & 3.87 & 55,11 & 3.91 \\
\hline & Discrim. & 6.61 & .83 & 6.67 & .58 & 5.61 & 1.30 & 6.39 & .68 \\
\hline & QMI & 78.22 & 21.96 & 89.06 & 17.04 & 75.33 & 20.15 & 70.22 & 15.78 \\
\hline & QWT & 77.22 & 14.92 & 77.11 & 11.76 & 82.17 & 8.91 & 79.28 & 12.71 \\
\hline
\end{tabular}




\section{Procedure}

Since the procedure was essentially the same for both experiments, it will be described jointly. Ss completed the two questionnaires (QMI and QWT) before the experimental session, usually on the ward. The experimental session was carried out in a research trailer. All Ss first completed a visual discrimination task ( 2 simple and 5 complex patterns) in which they were required to match two patterns - the target stimulus was located in the upper central portion of the slide whereas the matching pattern was randomly located in one of 6 locations below the target pattern. After completion of this task, a brief rest period ensued, then $\underline{S}$ s read the instructions for the next part of the experiment.* Each of the $\underline{S} s$ looked at 4 equivalent blocks of 10 slides, the order of presentation of these being partially counterbalanced so that a $\underline{S}$ could be presented with a) a recall or a recognition task first, b) a delay or no delay condition first. In effect there were 4 orders of presentation of slide blocks, each block of 10 slides having different instructions. Five minute breaks were taken between each set of 10 slides. A brief questionnaire was administered after the 4 th set in Experiment II but not in Experiment I. The major difference between the two experiments was in pacing, i.e., in Experiment I, Ss determined their own viewing time whereas in Experiment II, viewing time was fixed at either 3,6 , or 12 seconds. In the self-paced condition, $\underline{S}$ terminated slide presentation by pressing a button which was attached to their desk. Taperecorded instructions (e.g., "Ready", "Wait", "Go ahead") were timed so that each $\underline{\mathrm{S}}$ had a 15 second response period and in the delay condition, a 5 second waiting period. In recall, $\underline{5} s$ checked 
off those squares in blank matrices on answer sheets, which corresponded to filled squares in stimulus patterns. In recognition, $\underline{S} s$ placed check marks in one out of six blank squares provided on answer sheets. In both conditions, one answer sheet was provided for each slide used. The Ss were seated 5 feet from the screen.

Design

In Experiment I, a $2 \times 2 \times 2 \times 2$ design was used with repeated measures on the last two factors, e.g., delay and complexity. The factors were: age (young and older), sex (male and female), delay ( 5 seconds and no delay), and stimulus complexity ( 6.1 and 13.7 bits). In Experiment II, another variable was added, e.g., viewing time $(3,6$, or 12 seconds). In effect, it was a repeated measures design $(2 \times 2 \times 3 \times 2 \times 2)$ with repeated measures on the last two factors (delay and complexity again).

In both experiments, the first response in each block of 10 was omitted from the analysis in order to minimize position effects. The last response was also omitted in order to maintain a balanced design. Mean values per subject per condition were used in the analysis of recall scores and self-paced time requirements. Each of these mean values was based on 4 raw scores. In the analysis of recognition scores, the total number of correctly recognized patterns by each subject in each condition was used. Order of presentation of stimulus blocks was counterbalanced* and confounding of order effects was assumed in the analysis (Gaito, 1961).

* Refer to p. 25 for details 


\section{RESULTS}

Experiment I

The analysis of the data for Experiment I consisted of a $2 \times 2 \times 2 \times 2$ (age, sex, complexity and delay respectively) analysis of variance with repeated measures on the last two factors. Four dependent variables were investigated: a) self-paced viewing times for recall tasks, b) self-paced viewing times for recognitions tasks, c) recall scores, and d) recognition scores.

The analysis of variance of recall memory scores (Appendix II, Table 1) showed complexity to be the only significant factor (simple = 15.55, complex $=14.27$ ). Recognition scores (Appendix II, Table 2) varied as a function of the interaction between age and complexity (young, simple $=3.58$, young, complex $=3.75$, older, simple $=3.54$, older, complex $=$ 3.17). Scheffe's test (Appendix IV) showed that while older Ss performed as well as the young on simple tasks, their performance on complex tasks decreased significantly.

The analysis of variance of self-paced viewing times with recall tasks (Appendix II, Table 3) showed the following factors to be significant: delay (delay $=10.96$, no delay $=8.99$ ), complexity $($ simple $=7.52$, complex $=12.19$ ), and the delay by complexity interaction (simple, delay $=8.91$, simple, no delay $=6.12$, complex, delay $=12.51$, complex, no delay $=11.87)$. While viewing time decreased with both simple and complex tasks for delayed vs. immediate recal1, the decrement associated 
with simple tasks was much larger than that associated with complex tasks. Despite a relatively large difference in viewing time between young and older $\underline{S}$ (young $=8.15$, older $=11.56$ ), the main effect for age was not significant $(p<.20)$.

Self-paced viewing time for recognition tasks (Appendix II, Table 4) varied as a function of: age (young $=5.73$, older $=9.39$ ), complexity (simple $=6.37$, complex $=8.75$ ), the delay by sex by complexity interaction (Table 2a), and the age by sex by delay be complexity interaction (Table 2b). Scheffe's test was used to investigate further the last two interactions. 01der people took more time to view the stimuli but this behavior was related to pattern complexity, retrieval delay and sex. Young males had the shortest viewing times, young females came next, older males came third and older females last. In addition, older females had the least predictable patterns of viewing time in that the other three groups generally exhibited an increase in viewing time from simple to complex tasks and from immediate to delayed retrieval (with the exception of young males who had similar durations for both delayed and immediate retrieval). 01der females had rather long viewing times across all conditions.

Comparisons of the four age by sex groups (young males, young females, older males, older females) with regard to demographic data (age, visual discrimination task, QMI and QWT) were made (t-tests, Appendix VI, Tables $1 a, 1 b, 1 c, 1 d)$. Except for obvious age differences between the young and older groups, no significant differences were obtained. Important was the finding of no difference between the two age groups on the visual discrimination task. This finding suggests that differences in visual acuity between young and older individuals did not 
TABLE 2 (a)

Mean viewing times for the sex by delay by complexity interaction (Experiment I, recognition task)

\begin{tabular}{rccccc} 
& \multicolumn{2}{c}{ No Delay } & \multicolumn{2}{c}{ Delay } \\
& Simple & Complex & & Simple & Complex. \\
Male & 5.46 & 8.09 & & 5.66 & 8.61 \\
Female & 6.68 & 9.30 & 7.69 & 9.00
\end{tabular}

TABLE 2 (b)

Mean viewing times for the age by sex by delay by complexity interaction (Experiment I, recognition task)

\begin{tabular}{rrrrrrr} 
& & \multicolumn{2}{c}{ No Delay } & \multicolumn{2}{c}{ Delay } \\
& & Simple & Complex & Simple & Complex \\
\multirow{2}{*}{ Young } & Male & 4.20 & 6.43 & 3.85 & 6.31 \\
& Female & 5.09 & 6.96 & 5.36 & 7.61 \\
\multirow{2}{*}{ 01der } & Male & 6.73 & 9.74 & 7.46 & 10.91 \\
& Female & 8.27 & 11.64 & 10.01 & 10.39
\end{tabular}


exist.

Similar t-test comparisons were made with respect to education (Appendix XII, Table 1a). Two significant differences were observed, i.e., young females were better educated than either older males or older females. No particular significance can be attached to this finding, however, in view of the correlational analyses (Appendix XII, Tables 2a, 2b). Significant correlations were observed between educational level and: a) age, b) recognition memory performance. After the effects of age were partialled out from the correlation between educational level and recognition memory performance, it became statistically non significant. None of the remaining correlations between educational level and subject characteristics reached statistical significance.

Other correlational analyses were performed (Appendix VII, Table 1). Of prime importance in this research were the correlations between age and: a) subject characteristics, b) self-paced viewing time, and c) STM performance. Only two of these correlations were significant, i.e., that between age and viewing time and that between age and decreasing recognition memory performance. Both findings have been described above in the analysis of variance results section.

\section{Experiment II}

The data analysis for Experiment II consisted of a $2 \times 2 \times 3 \times 2 \times 2$ (age, sex, viewing time, complexity and delay, respectively) analysis of variance with repeated measures on the last two factors. Recall and recognition memory scores comprised the dependent variables.

The analysis of variance of recall memory scores showed retrieval to be a function of the following factors: age (young $=14.99$, older $=$ 14.17), complexity $($ simple $=15.47$, complex $=13.68)$, viewing time $(3 \mathrm{sec} .=$ 
$14.08,6 \mathrm{sec} .=14.75,12 \mathrm{sec} .=14.91)$, and the age by viewing time interaction (Figure 3). Scheffe's test applied to the means of the interaction, showed that age related decrements in STM performance occurred only with the $3 \mathrm{sec}$. viewing time.

The analysis of variance of recognition memory scores showed significant effects for the following factors: age (young $=3.59$, older $=3.29)$, viewing time $(3 \mathrm{sec} .=3.27,6 \mathrm{sec} .3 .42,12 \mathrm{sec} .=3.63)$, delay (no delay $=3.31$, delay $=3.56)$, complexity $($ simple $=3.61$, complex $=3.27$ ), the sex by viewing time interaction (Table 3a), the age by delay interaction (Table 3b), the age by viewing time by delay by complexity interaction (Table 4) and the age by sex by viewing time by delay by complexity interaction (Table 5). All of the foregoing interactions were tested using Scheffe's test. Significant main effects suggest that age, viewing time, complexity and delay play important roles in recognition memory performance such that young $\underline{S} \mathbf{s}$ do better than older $\underline{S} s$, simple stimuli are recalled better than complex one, longer viewing times lead to better performance and delayed recall is superior to immediate recall. These conclusions are tempered by the significant interactions. The age effect seems to be a direct function of immediacy of retrieval such that older $\underline{S}$ do badly with immediate recall but perform as well as the young with delayed recall in most instances. The significance of the main delay effect is due largely to the above interaction also as the young $\underline{S} \mathbf{s}$ perform equally well with both delayed and immediate recall. The age effect is also related to viewing time and task complexity such that STM performance improves with increasing viewing time, simpler stimuli and delayed recall. Sex effects complicate the issue somewhat, the general trend being that males perform well at 6 and $12 \mathrm{sec}$. viewing time and poorly at $3 \mathrm{sec}$. , and females do better at 3 and $12 \mathrm{sec}$. but poorly at 


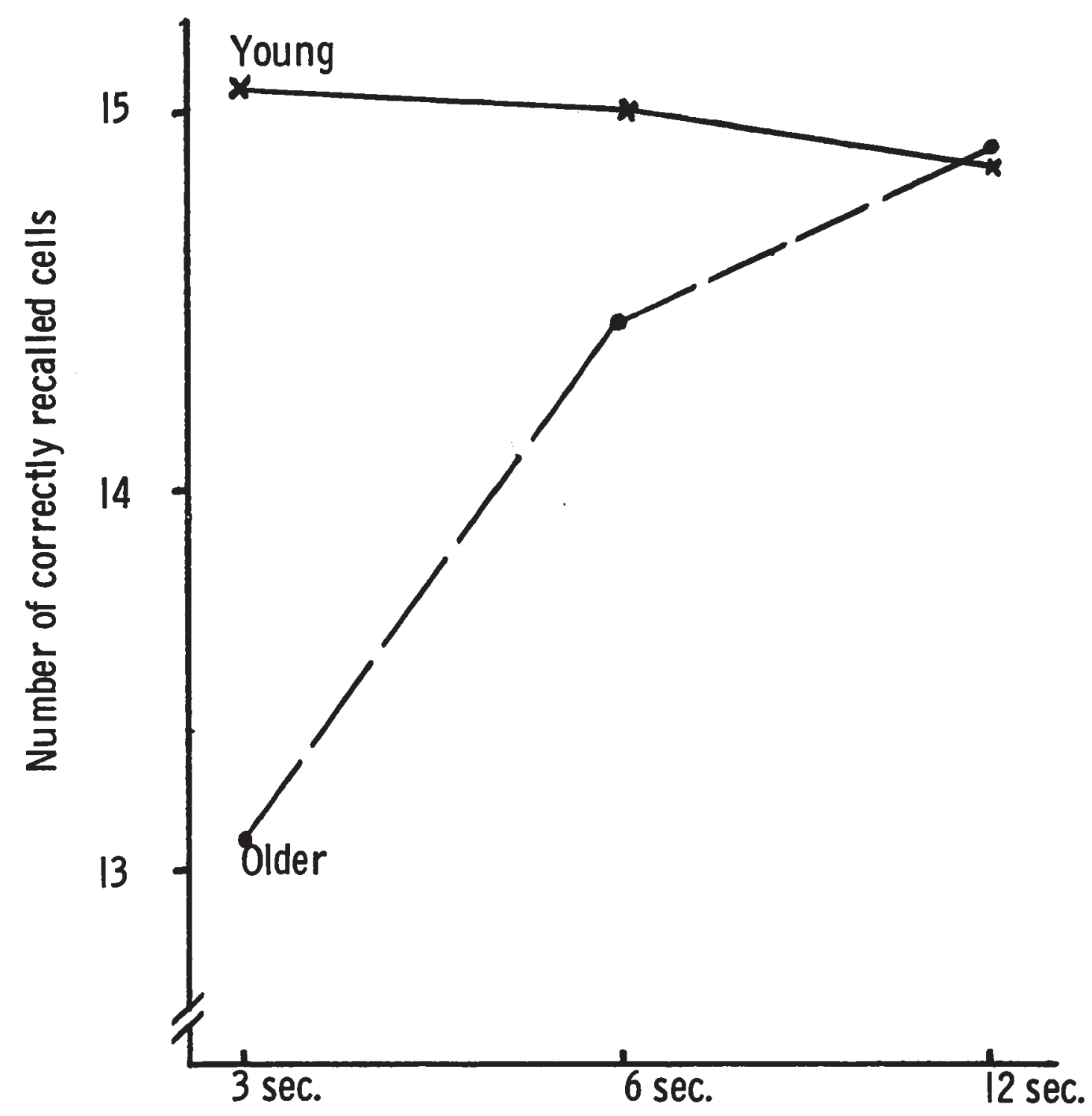

Figure 3. Recall as a function of viewing time and age. 


\section{TABLE 3 (a)}

Mean recognition memory scores for the sex by viewing time interaction. (Experiment II)

\begin{tabular}{|c|c|c|c|}
\hline & 3 sec. & $6 \mathrm{sec}$. & $12 \mathrm{sec}$. \\
\hline Male & 3.18 & 3.70 & 3.67 \\
\hline Female & 3.35 & 3.14 & 3.60 \\
\hline
\end{tabular}

TABLE 3 (b)

Mean recognition memory scores for the age by delay interaction (Experiment II)

\begin{tabular}{lcc} 
& No Delay & Delay \\
\cline { 2 - 3 } Young & 3.58 & 3.59 \\
OTder & 3.05 & 3.54
\end{tabular}




\section{TABLE 4}

Mean recognition memory scores

for the age by complexity by delay by viewing time interaction

(Experiment II)

$3 \mathrm{sec} .6 \mathrm{sec} .12 \mathrm{sec}$.

\begin{tabular}{|c|c|c|c|c|c|}
\hline \multirow{2}{*}{ YOUNG } & No Delay & $\begin{array}{l}\text { Simple } \\
\text { Complex }\end{array}$ & $\begin{array}{l}3.75 \\
3.33\end{array}$ & $\begin{array}{l}3.75 \\
3.33\end{array}$ & $\begin{array}{l}3.75 \\
3.58\end{array}$ \\
\hline & Delay & $\begin{array}{l}\text { Simple } \\
\text { Complex }\end{array}$ & $\begin{array}{l}3.58 \\
3.33\end{array}$ & $\begin{array}{l}3.97 \\
3.41\end{array}$ & $\begin{array}{l}3.91 \\
3.41\end{array}$ \\
\hline \multirow{2}{*}{ OLDER } & No Delay & $\begin{array}{l}\text { Simple } \\
\text { Complex }\end{array}$ & $\begin{array}{l}2.66 \\
2.83\end{array}$ & $\begin{array}{l}3.25 \\
2.75\end{array}$ & $\begin{array}{l}3.66 \\
3.16\end{array}$ \\
\hline & Delay & $\begin{array}{l}\text { Simple } \\
\text { Complex }\end{array}$ & $\begin{array}{l}3.66 \\
3.00\end{array}$ & $\begin{array}{l}3.66 \\
3.33\end{array}$ & $\begin{array}{l}3.83 \\
3.75\end{array}$ \\
\hline
\end{tabular}




\section{TABLE 5}

Mean recognition memory scores for the age by sex by complexity by delay by viewing time interaction (Experiment II)

\begin{tabular}{|c|c|c|c|c|c|c|c|c|}
\hline & \multicolumn{3}{|c|}{ No Delay } & \multicolumn{3}{|c|}{ Delay } \\
\hline & & & 3 & 6 & 12 & 3 & 6 & 12 \\
\hline \multirow[b]{2}{*}{ YOUNG } & Male & $\begin{array}{l}\text { Simple } \\
\text { Complex }\end{array}$ & $\begin{array}{l}3.50 \\
3.50\end{array}$ & $\begin{array}{l}4.00 \\
3.30\end{array}$ & $\begin{array}{l}4.00 \\
3.66\end{array}$ & $\begin{array}{l}3.66 \\
3.16\end{array}$ & $\begin{array}{l}4.00 \\
4.00\end{array}$ & $\begin{array}{l}4.00 \\
3.50\end{array}$ \\
\hline & Female & $\begin{array}{l}\text { Simple } \\
\text { Complex }\end{array}$ & $\begin{array}{l}4.00 \\
3.16\end{array}$ & $\begin{array}{l}3.50 \\
3.33\end{array}$ & $\begin{array}{l}3.50 \\
3.50\end{array}$ & $\begin{array}{l}3.50 \\
3.50\end{array}$ & $\begin{array}{l}3.83 \\
2.83\end{array}$ & $\begin{array}{l}3.83 \\
3.33\end{array}$ \\
\hline \multirow[b]{2}{*}{ OLDER } & Male & $\begin{array}{l}\text { Simple } \\
\text { Complex }\end{array}$ & $\begin{array}{l}2.66 \\
2.50\end{array}$ & $\begin{array}{l}3.83 \\
3.00\end{array}$ & $\begin{array}{l}3.83 \\
2.83\end{array}$ & $\begin{array}{l}3.50 \\
3.00\end{array}$ & $\begin{array}{l}4.00 \\
3.50\end{array}$ & $\begin{array}{l}3.83 \\
3.66\end{array}$ \\
\hline & Female & $\begin{array}{l}\text { Simple } \\
\text { Complex }\end{array}$ & $\begin{array}{l}2.66 \\
3.16\end{array}$ & $\begin{array}{l}2.66 \\
2.50\end{array}$ & $\begin{array}{l}3.50 \\
3.50\end{array}$ & $\begin{array}{l}3.83 \\
3.00\end{array}$ & $\begin{array}{l}3.33 \\
3.16\end{array}$ & $\begin{array}{l}3.83 \\
3.83\end{array}$ \\
\hline
\end{tabular}


6 seconds. A comparison of age related decrements in recall and recognition tasks in relation to delay, yields the following data: recall, no delay $=90 \%$, recal1, delay $=90 \%$, recognition, no delay $=85 \%$, recognition, delay $=95 \%$. Figures given denote recall capability of older $\underline{S}$ expressed as a percentage of that of young $\underline{S}$. This comparison (along with the analysis of variance results) suggests that age related decrements in immediate recognition memory are reliable.

Demographic data (age, visual discrimination task, QMI and QWT) for the four age by sex groups were analyzed by t-tests (Appendix VI, Tables 2a, 2b, 2c, and 2d). Of the 24 comparisons made, 5 differences were significant. Four of these involved chronological age and the remaining one showed a difference in imaging ability (QMI) between young and older females. Little significance can be attached to this finding, however, as correlational analyses (Appendix VII, Table 5) showed STM performance to be unrelated to QMI scores. Of importance is the finding of no age related differences on the visual discrimination task suggesting that no differences in visual acuity existed between young and older $\underline{S}$. Additional t-test analyses involved the educational level of young and older $\underline{S} s$ and no significant differences were observed in that regard (Appendix XII, Table Ib).

Correlational analyses of interrelations between demographic variables, STM performance and post-experimental questionnaire results were performed (Appendix VII, Tables 2, 3, 4, and 5). Of importance in this research, were the correlations between age and: a) pre-test variables, b) STM performance, c) inquiry results. Of the 40 correlations in question, 7 were statisticaliy significant. Four of these were negative correlations between STM performance and age. Of the remaining three 
two dealt with high incidence of "counting" by older $\underline{S} s$ at the $3 \mathrm{sec}$. viewing time (Appendix IX, Table 1) and low use of "other" encoding techniques. Partialling out the effects of "counting", however, did not substantially reduce the negative correlations between STM performance and age at the $3 \mathrm{sec}$. viewing time (Appendix VII, Table 6). The remaining coefficient depicted a negative relationship between age and imaging ability at the $6 \mathrm{sec}$. viewing time. Since the correlations between age and STM performance, and imaging ability and STM performance are not statistically significant ( 6 sec. viewing time), little importance can be attached to this result. In effect, analysis of QMI, QWT, discrimination task and post-task questionnaire responses, did not suggest any reliable relationships between STM performance and subject characte istics assessed by these instruments.

Summary of the Results

Integration of the results of Experiments I and II, leads to the following conclusions: 1) 01der $\underline{S}$ took longer to view the stimuli with recognition tasks. With recall tasks, this trend was not significant. 2) Age related decrements in visual STM took place with recall tasks if stimulus viewing time was too short. 3) Age related decrements in visual STM took place with recognition tasks. These decrements were related to stimulus complexity (self-paced condition) and stimulus complexity, viewing time, delay and sex (paced conditions). 4) Analys is of encoding methods did not suggest any reliable relationships between STM performance and encoding strategies. 


\section{DISCUSSION}

Past research findings do not provide answers for a number of questions regarding age related changes in visual STM. These questions include: 1) is there an age related slowing of encoding at the registration phase and what effects does it have on visual STM? 2) is there an age related decrement in visual STM with delayed recall? 3) is there an age related retrieval deficit in visual STM? 4) are there age related differences in encoding methods with visual, nonverbal stimuli and are these related to STM performance? It was the aim of this dissertation to clarify the foregoing issues. The results obtained in this study will be discussed in relation to the three phases underlying STM, i.e., registration, storage and retrieval. The results will also be related to other variables which significantly affect STM performance of older adults.

\section{REGISTRATION}

The results of the present research suggest that older adults exhibit a slowing of information processing at the registration phase. This finding is consistent with the results obtained in studies of perceptual processes as a function of age but is inconsistent with findings obtained in STM studies using simple verbal stimuli. The duration of the registration phase has been found to be of little importance in STM for verbal items. This discrepancy is not surprising. 
In his discussion of the processes underlying identification and storage of printed and spoken linguistic items, Norman (1970) points out that by the time the verbal symbol has entered sensory storage, its meaning has probably been deciphered and little attention has centered on its physical characteristics. He states that a good deal of evidence indicates that language symbol identification is extremely quick. Norman (1970) asserts that somewhere between the sensory storage system and short-term memory the sensory image becomes analyzed, identified and interpreted. In this investigation, a three second viewing time for the older Ss probably does not allow the sensory image to be fully analyzed and its features extracted. The data obtained in this study are difficult to interpret when attempting to specify the precise mechanisms underlying information processing slowing of the older $\underline{S} s$. The data do suggest that mediational coding, while differing to some extent between the younger and the older groups, was of little importance in determining STM performance. Performance on the visual discrimination task as well as the QWT and QMI scores did not differ significantly between the young and the older groups. Furthermore, these variables did not correlate significantly with subject recall scores. The questionnaire results suggest that with short viewing times, some differences in coding strategies existed between the two age groups but these differences did not contribute significantly to STM performance. While the elderly concentrated on "counting" at the three second viewing time, partialling out the effects of this strategy did not decrease the age differences appreciably. The other methods of coding stimuli for recall, i.e., "imaging" and "similarity to other subjects", did not correlate signi- 
ficantly with recal1. Thus, the results of the present study do not support the hypothes is that inadequate coding methods account for slower information processing of older adults at the registration phase. This finding can be contrasted with the results reported by other researchers. Paivio (1971) concluded that in learning concrete stimulus materials, young subjects use predominantly imaginal mediators. With abstract stimulus materials, mostly verbal mediators are used. Paivio (1971) observed that imaginal coding of concrete items is more effective than verbal coding in PA learning. The fact that imagery plays a minor role in visual STM in this research, is probably attributable to differences in stimuli, a view which Paivio (1971) shares. The stimuli used in this research are non-representational, abstract, geometric patterns and are, therefore, not easily amenable to coding. Hulicka and her colleagues have suggested that age related changes in coding methods include an absolute decrease in the number of mediators used and a predominant use of verbal mediators. The data of this research suggest that age related differences in the use of strategies were small and of little importance to recall performance. Canestrari's (1968) results are consistent with this finding. He observed no differences in PA learning in relation to type of strategy used (imagery or verbal) for either of the age groups. More recently, Rowe and Schnore (1971) explored the relationship between abstractness of stimuli of a PA task and type of strategy used by young, middle aged and aged subjects. The authors observed that the aged used fewer mediators than the young, but they did not find an age by strategy interaction as would have been suggested by Hulicka. In other words, no differences were observed between the use of imaginal and verbal 
strategies by the young and old individuals. Any age related differences in mediational coding have not been clearly specified by research to date and further research is needed in order to define their role in age related decrements in learning and remembering.

To summarize, the results obtained in this research suggest that age related slowing in information processing does take place during the registration phase. This slowing is responsible for poorer STM performance of the older group with short viewing time. The precise mechanism underlying this slowing needs elucidation by further research. For example, slower eye movements of older individuals could be responsible for their inadequate performance. This hypothesis is consistent with the visual information processing model advanced by Noton and Stark (1971). Using sophisticated recording techniques, these researchers photographed eye movements made by the $\underline{S}$ while examining various stimulus materials. Noton and Stark observed that each subject had a characteristic pattern of fixations and saccades (rapid eye movements) for each stimulus figure. These patterns were both subject and stimulus specific. On the basis of their findings, Noton and Stark (1971) postulated the following visual learning and visual recognition mechanisms:

1) inspection of a visual stimulus leads to an internal neural representation of the stimulus, 2) this representation is arrived at in a discrete, serial process of fixations, 3) the pattern of fixation on various features of the stimulus results in a "feature ring" which is subject and stimulus specific, 4) in recognition tasks, the subject recognizes the correct figure because his stored "feature ring" matches that of the answer stimulus. Each feature ring consists of the sensory 
memory traces of the object as well as motor memory traces of the eye movements. This mechanism can be easily related to the organic and experiential aging effects theories. Organic theory (Carpenter and Loynd, 1968) states that the elderly are slower in neural functioning and are susceptible to increased amounts of "neural noise". This would lead to less well rehearsed and less stable rings. Experiential theory (Schnore, 1971) states that the elderly are subject to proactive transfer effects. Such transfer effects would include cautiousness and inefficient scanning of novel geometric patterns. As a result, the elderly would be slower in establishing feature rings which would then be less well rehearsed than those of the young.

STORAGE

Past research has shown that if a delay is introduced between stimulus offset and response onset, age related decrements in STM usually take place. These decrements have been ascribed to either increased memory trace decay, or increased interference effects, or both. In the present study, the results sugges t that age related memory trace decay did not take place. Since the interpolated task delay method was not used in this study, little can be said about interference effects. The foregoing findings are inconsistent with those obtained by other researchers who employed other types of stimuli (Inglis, 1965). Methodological variables, however, are probably responsible for the discrepancy, as the $5 \mathrm{sec}$. delay interval with the present stimuli was too short to produce significant effects on STM performance. Results associated with the age by delay interaction support this notion. While 
a clear-cut age effect was observed with recall performance, neither a delay effect nor a delay by age interaction effect was evident. With recognition tasks, older $\underline{S}$ s performed as well as the young with delayed recall but deteriorated with immediate recall (Table $3 \mathrm{~b}$ ). This finding suggests that with the visual stimuli used in this study, there is a need for a post registration consolidation period during which neural integration of the stimulus pattern might take place. RETRIEVAL

The results of the present research do not support a specific retrieval deficit in older adults because older $\underline{S}$ s showed visual STM decline in both recall and recognition tasks. Since the response period consisted of 15 seconds, problems with regard to response mobilization are not likely to have affected subject performance. Most of the $\underline{S}$ completed their answers rather quickly and were usually waiting for the "ready" signal before the onset of the next slide. Although older $\underline{S}$ exhibited greatest recognition memory decrements when retrieval was immediate -- suggesting the presence of strong interference effects -their performance with complex tasks and self-paced viewing time was also poorer than that of the young (Experiment I). In effect, older $\underline{S} s$ showed reliable decrements in their recognition memory performance. This finding is inconsistent with the results reported by Schonfield and Robertson (1966) who observed recall but no recognition memory decrements with older $\underline{S} s$. Since the absence of age related recognition memory decrements comprises the essential evidence for the retrieval deficit hypothesis, the results of this study argue strongly against Schonfield's retrieval deficit hypothesis. The foregoing results are in agreement with the findings of Johnson (1966), Caird (1965) and McNulty and Caird 
(1967). In each of the latter studies age related differences in recognition memory were observed.

The results suggest that the older $\underline{S} s$ were particularly sensitive to interference effects at the retrieval phase. In this research, the interference effects appeared to have been caused by the different alternatives of the answer slide. This finding is consonant with the findings of others. Kline (1970) observed that older $\underline{S} s$ displayed poorer STM performance than young $\underline{S}$ s when visual noise was presented shortly after stimulus presentation. This would suggest that the crucial period regarding interference effects is immediately following stimulus offset and is of brief duration. Laurence (1966) supports this hypothesis. She found that with a two second presentation rate and immediate (or briefly delayed retrieval), the elderly performed less well than the young in a PA verbal learning task. This age difference disappeared with delayed recall. It should be noted that in the latter two studies, STM performance was determined by the recall method. In Kline's study, interference would have been provided by the visual noise which the subjects could not avoid, and in Laurence's study, aural responding may have been the source of interference. In effect, despite divergent methodologies, a common conclusion is derived from the results of the three studies discussed. To conclude, since age related decrements in visual STM performance occurred with both recall and recognition tasks, Schonfield's retrieval deficit hypothesis is not supported. The results do suggest that age related decrements in visual STM are a function slowing of information processing at the registration phase and increased susceptibility to interference just after the registration phase. 


\section{RELATED VARIABLES}

In cross-sectional studies, a number of variables tend to be confounded with aging effects (Hulicka, 1967). These include cautiousness, motivation, intelligence, and health. A number of investigators have found an age related slowing in performance which they attributed to excessive cautiousness in the elderly rather ti:an to changes in the speed of neural processes. Korchin and Basowitz (1957) used ambiguous drawings and concealed figures in an identifying task. They observed that the elderly performed worse than the young mainly because they avoided guessing. The authors ascribed poor performance of the aged to "excessive cautiousness". Wallach and Kogan (1961) examined cautiousness in relation to age. Their task consisted of making choices in hypothetical life situations where one choice was risky but rewarding and the other safer but less rewarding. The elderly chose the latter alternative more often than the young which would suggest that they are more cautious. In effect then, apparent slowness of the elderly in experimental tasks can be attributed to their greater emphasis on accuracy rather than speed. This stress on accuracy would probably be the result of Ss' past experiences (Schnore, 1971). The results obtained in this research suggest that cautiousness was partly responsible for the test behavior of the elderly. While in the self-paced condition, the average VT of the aged was about 9 to 10 seconds, their performance under those conditions did not differ substantially from their performance at 6 seconds (paced condition). 
An attempt was made to control for some of the other concomitant variables in the current study. Subjects consisted of younger and older employees of a psychiatric hospital who volunteered and were paid a gratuity for their participation. Many of the $\underline{\text { s }}$ (both young and older) expressed concern about doing a good job and voiced a desire to receive feedback regarding their performance. 01der $\underline{S} s$ frequently stated that they did a good job on some patterns but not on others. These behaviors suggest that the older $\underline{\text { Ss }}$ were motivated to do well. Verbal IQ scores were not significantly different for the two groups even though the older sample had greater mean values. All of the $\underline{S} s$ were in good health and displayed adequate vision for the purposes of this experiment. Several had to be rescheduled because they neglected to bring their glasses with them the first time.

Sex effects were variable and are not easily interpretable. In general, the males tended to perform better than the females. There were no notable sex differences on pre-test variables. Heron and Chown (1967) postulated that those sex differences which they observed with Memory-for-Designs test scores may have been related to verbal-perceptual differences in that females tend to perform better on verbal tasks and males on mechanical-perceptual tasks. Some of the differences between males and females may be attributed to cautiousness as for example in Experiment $\dot{I}$, older females had uniformly long viewing times. Where sex differences did occur, young males usually performed best, young females came second, older males third and older females last. 


\section{SUMMARY AND CONCLUSIONS}

The results obtained in this research suggest that in comparison to the young, older adults are hindered in their visual STM performance because of slower information processing at the registration phase as well as a greater susceptibility to interference just following the registration phase. The data do not provide support for a retrieval deficit hypothesis as espoused by Schonfield. The hypothesis of age related increases in memory trace decay is not supported either. The results suggest that mediational coding differences between younger and older $\underline{S}$ s contribute little to age related registration phase difficulties. The precise mechanism underlying those difficulties, however, requires elucidation by further research. Such a mechanism could be mediated by either organic deterioration of the CNS (Carpenter and Loynd, 1968) or experiential transfer effects (Schnore, 1971). 


\section{SUGGESTIONS FOR FUTURE RESEARCH}

Hypotheses explaining age related STM changes have been postulated throughout this dissertation. Some of these hypotheses are supported by research findings whereas others require confirmation and elucidation by further research. One of the basic questions concerns the role of organic deterioration and experiential transfer effects in cognitive functioning of older people. Empirical estimates of the magnitude of each and/or their interaction, would have significant implication for the rehabilitation and care of the aged. Another basic question concerns the mechanism underlying visual STM functioning in older adults. A tentative mechanism has been described but extensive research is needed to test its veracity. A question raised directly by the results obtained in this dissertation involves the absence of age related memory trace decay -- isolation of the variables responsible for this finding would add to our knowledge of visual STM functioning. Another question concerns the role of mediational coding in learning and remembering of older people. Delineation of the most efficient coding strategies for older adults would be very useful in improving their cognitive functioning. A question worth exploring is that raised by the presence of age related interference effects with immediate recognition but not immediate recall tasks. Elucidation of the foregoing issues will have important implications for the management and well-being of our growing populations of older individuals as well as our understanding of human cognitive functioning. 


\section{REFERENCES}

Adamowicz, J. K. Visual short-term memory in alcoholics and normals. Unpublished manuscript, JuTy, 1971.

Arenberg, D. The anticipation interval and age differences in verbal learning. Journal of Abnormal Psychology, 1965, 70, 419-425.

Arenberg, D. Input modality in short-term retention of old and young aduits. Journal of Gerontology, 1968, 23, 462-465.

Attneave, F. Symmetry, information, and memory for patterns. American Journal of Psychology, 1955, 68, 209-222.

Attneave, F. Applications of Information Theory to Psychology. New York: Henry Hott \& Co., 959 .

Benton, A. L. The revised visual retention test: clinical and experimental applications. State University of lowa Press, lowa City, 1955.

Billingslea, F. Y. The Bender-Gestalt: a review and a perspective. Psychological Bulletin, 1963, 60, 233-251.

Blakemore, C. B. A critique of the Bender-Gestalt. In 0. K. Buros (Ed.) The Sixth Mental Measurement Yearbook. The Gryphon Press, New Jersey, 1965, p. 203.

Broadbent, D. E. Immediate memory and simultaneous stimuli. Quarterly Journal of Experimental Psychology, 1957, $9,1-11$.

Brown, D. R. and Owen, D. H. The metrics of visual form: methodological dyspepsia. Psychological Bulletin, 1967, 68, 243-259.

Bruce, D. and Cofer, C. N. A comparison of recognition and recall in short-term memory. Proceedings, 73rd Annual Convention of the American Psychological Association, Chicago, 1965.

Bruning, J. T. and Schappe, R. H. Type of interpolated activity and short-term memory. Psychological Reports, 1965, 16, 925-929.

Caird, W. K. Memory disorder and psychological test performance in aged psychiatric patients. Diseases of the Nervous System, 1965, 26, 499-505. 
Cameron, P. Age parameters of young adult, middle-aged, old, and aged. Journal of Gerontology, 1969, 24, 201-202.

Canestrari, R. E., Jr. Age changes in acquisition. In G. A. Talland (Ed.) Human Aging and Behavior. New York: Academic Press, 1968.

Carpenter, D. G. and Loynd, J. A. An integrated theory of aging. Journal of the American Geriatrics Society, 1968, 16, 1307-1322.

Craik, F. I. M. Short-term memory and the aging process. In G. A. Taliand (Ed.) Human Aging and Behavior. New York: Academic Press, 1968.

Eisdorfer, C. Verbal learning and response time in the aged. Journal of Genetic Psychology, 1965, 107, 15-22.

Eisdorfer, C., Axelrod, S. and Wilkie, F. L. Stimulus exposure time as a factor in serial learning in an aged sample. Journal of Abnormal and Social Psychology. 1963, 67, 594-600.

Eriksen, C. W., Haml in, R. M. and Breitmeyer, R. G. Temporal factors in visuai perception as related to aging. Perception and Psychophysics, $1970, \underline{7}, 354-356$.

Gaito, J. Repeated measures designs and counterbalancing. Psychological Bulletin, 1961, 58, 46-54.

Gibson, J. Retroactive inhibition as a function of degree of generalization between tasks. Journal of Experimental Psychology, 1941, 28, 93-115.

Goldstein, L. D., Spielberger, C. D., Williams, J. E. and Dahlstrom, W. G. The effect of serial position and design difficulty on recall of the Bender-Gestalt Test Designs. Journal of Consulting Psychology, $1955,19,230-234$.

Graham, F. K. and Kendall, B. S. Memory-for-designs-test -- revised general manual. Perception and Motor Skills, 1960, 11, 147-190.

Hannah, L. D. Causative factors in the production of rotations on the Bender-Gestalt Designs. Journal of Consulting Psychology, 1958, 22, 398-399.

Hanawalt, N. G. A critique of the Benton Visual Retention Test. In 0 . K. Buros (Ed.) The Fifth Mental Measurement Yearbook.

The Gryphon Press: New Jersey, 1965, p. 401.

Heron, A. and Chown, S. Age and Function. London: J. \& A. Churchill, Ltd. , 1967. 
Hulicka, I. M. Age differences for intentional and incidental learning and recali scores. Journal of the American Geriatrics Society, $1965,13,639-649$.

Inglis, J. Immediate memory, age and brain function. In A. T. Welford and J. E. Birren (Eds.) Behavior, Aging and the Nervous System. Springfield: C. C. Thomas, T965.

Inglis, J. and Caird, W. K. Age differences in successive responses to simul taneous stimulation. Canadian Journal of Psychology, 1963, 17, 98-105.

Inglis, J. and Ankus, M. N. Effects of age on short-term storage and serial rote learning. British Journal of Psychology, 1965, 56, 183-195.

Jamieson, G. H. Prior learning and response flexibility in two age groups. Journal of Gerontology, 1969, 24, 179-184.

Johnson, A. A. Recognition memory for visual patterns as a function of age. Unpublished Master's Thesis. University of Western Ontario, 1966.

Keevil-Rogers, P. and Schnore, M. M. Short-term memory as a function of age in persons of above average intelligence. Journal of Gerontology, 1969, 24, 184-188.

Kenda11, B. S. Memory-for-designs performance for the seventh and eighth decades of 1ife. Perception and Motor Skil1s, 1962, 14, 399-405.

$\mathrm{Kl}$ ine, D. W. Age differences in backward monoptic masking. Paper presented at the 23rd Annual Meeting of the Gerontological Society, Toronto, October, 1970.

Korchin, S. J. and Basowitz, H. Age differences in verbal learning. Journal of Abnormal and Social Psychology, 1957, 54, 64-69.

Kriaucionas, $R$. The relationship of age and retention filled activity in short-term memory. Journal of Gerontology, 1968, 24, 184-188.

Laurence, M. W. Presentation rate and age effects on paired-associate recall over very brief intervals. Psychonomic Science, 1966, $\underline{6}$, 185-186.

McNulty, J. A. A partial learning model of recognition memory. Canadian Journal of Psychology, 1966, 20, 302-315.

McNulty, J. A. and Caird, W. K. Memory loss with age: retrieval or storage? Psychological Reports, 1966, 19, 229-230.

Michels, K. M. and Zusne, L. Metrics of visual form. Psychological Bulletin, 1965, 63, 74-86. 
Norman, D. A. Models of Human Memory. New York: Academic Press, 1970.

Noton, $D_{\text {. }}$ and Stark, $L$. Eye movements and visual perception. Scientific American, 1971, 224, 34-43.

Paivio, A. Abstractness, imagery and meaningfulness in paired-associate learning. Journal of Verbal Learning and Verbal Behavior, 1965, 4, 32-38.

Paivio, A. Imagery and Verbal Processes. Toronto: Holt, Rinehart \& Winston, 1971.

Paivio, A. and Yuille, J. C. Changes in associative strategies and paired-associative learning over trials as a function of word imagery and type of learning set. University of Western Ontario Research Bulletin \# 81, Department of Psychology, June, 1968.

Peek, R. M. and Storms, L. H. Judging intellectual status from the BenderGestalt. Journal of Clinical Psychology, 1958, 14, 296-299.

Postman, L., Jenkins, W. O. and Postman, D. L. An experimental comparison of active recall and recognition. American Journal of Psychology, $1948,61,511-519$.

Rowe, E. J. and Schnore, M. M. Item concreteness and reported strategies in paired-associate learning as a function of age. University of Western Ontario Research Bulletin \# 181, Department of Psychology, May, 1971.

Scheffe, H. A. The analys is of variance. New York: Wiley, 1967.

Schnore, M. M. Memory for visual patterns in elderly psychiatric patients and normals. Final Report, Grant \#57, Mental Heal th Foundation, 1969.

Schnore, M. M. Age related changes in cognitive functioning and proactive transfer effect. Personal Communication, May, 1971.

Schnore, M. M. and Partington, J. T. Immediate memory for visual patterns: symmetry and amount of information. Psychonomic Science, 1967, $\underline{8}, 421-422$.

Schonfield, D. Memory loss with age: acquisition and retrieval. Psychological Reports, 1967, 20, 223-226.

Schonfield, D. and Robertson, B. A. Memory storage and aging. Canadian Journal of Psychology, 1966, 20, 228-236. 
Sheehan, P. W. (a) Accuracy and vividness of visual images. Perceptual and Motor Skills, 1966, 23, 392-398.

Sheehan, P. W. (b) Functional similarity of imaging to perceiving: individual differences in vividness of imagery. Perceptual and Motor Ski11s, 1966, 23, 1011-1035.

Suci, G. J., Davidoff, M. D. and Surwil10, W. W. Reaction time as a function of stimulus information and age. Journal of Experimental Psychology, $1960,60,242-244$.

Tarpy, R. M., Glucksberg, S. and Lytle, L. D. Motivation and short-term retention: evidence for covert rehearsat. American Journal of Psychology, 1969, 82, 111-116.

Tarpy, R. M. and Marshall, J. F. Effects of interference in STM with minimum covert rehearsal. Psychological Reports, 1970, 24, $723-726$.

Taub, H. A. and Walker, J. B. Short-term memory as a function of age and response interference. Journal of Gerontology, 1970, 25, 177-183.

Tolor, A. and Schuiberg, H. An evaluation of the Bender-Gestalt Test. Springfield, I11.: Charles C. Thomas, 1963.

Wallace, J. G. Some studies of perception in relation to age. British Journal of Psychology, 1956, 47, 283-297.

Wallach, M. A. and Kogan, N. Aspects of judgment and decision making: interrelationships and changes with age. Behavioral Science, $1961, \underline{6}, 23-26$.

Welford, A. T. Aging and Human Skill. London: Oxford University Press, 1958.

Welford, A. T. Performance, biological mechanisms and age: a theoretical sketch. In A. T. Welford and J. E. Birren (Eds.) Behavior, Aging, and the Nervous System. Springfield, I11.: Charles C. Thomas, 1965.

Williams, J. R. and Fish, D. L. Effects of item length and number of different elements on immediate memory. Psychonomic Science, $1965, \underline{3}, 353-354$.

Winer, B. J. Statistical Principles in Experimental Design. Toronto: McGraw-HiTT, 1962. 
APPENDICES

$\begin{aligned} \text { I } & \text { Definition of Terms } \\ \text { II } & \text { Analysis of Variance Summary Table (Experiment I) } \\ \text { III } & \text { Analysis of Variance Summary Table (Experiment II) } \\ \text { IV } & \text { Scheffe's Tests (Experiment I) } \\ V & \text { Scheffe's Tests (Experiment II) } \\ \text { VI } & t \text { Tests for Demographic Data } \\ \text { VII } & \text { Correlational Analyses } \\ \text { VIII } & \text { Post-experimental Inquiry } \\ \text { IX } & \text { Post-experimental Inquiry Results } \\ X & \text { Raw Data (Experiment I) } \\ X I & \text { Raw Data (Experiment II) } \\ \text { XII } & \text { Analysis of Educational Levels } \\ X I I I & \text { Methodological Details }\end{aligned}$


APPENDIX I 
The Ss participating in this research, are usually described as "older" adults, "older" Ss, and so on. The term "older" as used in this dissertation refers to people aged between 47 and 65 with a mean age of about 55. In a survey of 571 persons aged 11 to 80 , Cameron (1969) found that the term "young adult" was usually applied to people between the ages of 18 and 25, "middle aged" to people between the ages of 40 and 55, "old" to people aged 65 to 80 and "aged" to those over 80 . Researchers generally abide by these parameters even though some include 50 year olds in their old group (Johnson, 1966) and some select an arbitrary cutoff point, for example age 40, at which to divide their groups (Jamieson, 1969). In this dissertation, whenever the terms "old" and "elderly" are used, they refer to those aged 65 to 80 and the term "aged" refers to those over 80 .

The reader is cautioned to bear in mind the foregoing considerations when relating the results of this investigation to those reported by other researchers. The fact that significant decrements in visual STM did take place with the sample of subjects used in this study, sugges ts that the age effect is reliable and would probably increase in magnitude with older subject samples. 


\section{APPENDIX II}

Experiment I $F$ tables. 


\section{TABLE 1}

ANALYSIS OF VARIANCE OF RECALL MEMORY SCORES

\begin{tabular}{|c|c|c|c|}
\hline Source & $d f$ & MS & $F$ \\
\hline $\begin{array}{l}\text { Age (A) } \\
\text { Sex (S) } \\
A \times S \\
\text { Error (Ss) }\end{array}$ & $\begin{array}{r}1 \\
1 \\
1 \\
20\end{array}$ & $\begin{array}{r}1.20 \\
.01 \\
.71 \\
2.29\end{array}$ & $\begin{array}{l}<1.00 \\
<1.00 \\
<1.00\end{array}$ \\
\hline $\begin{array}{l}\text { Delay }(D) \\
A \times D \\
S \times D \\
\text { A X } S \times D \\
\text { Error }\left(\begin{array}{lll}\underline{S} s & X & D\end{array}\right)\end{array}$ & $\begin{array}{r}1 \\
1 \\
1 \\
1 \\
20\end{array}$ & $\begin{array}{r}.79 \\
.47 \\
1.82 \\
.05 \\
1.11\end{array}$ & $\begin{array}{r}<1.00 \\
<1.00 \\
1.64 \\
<1.00\end{array}$ \\
\hline $\begin{array}{l}\text { Complexity (C) } \\
\text { A XC } \\
S \times C \\
A \times S \times C \\
\text { Error }(\underline{S} S \times C)\end{array}$ & $\begin{array}{r}1 \\
1 \\
1 \\
1 \\
20\end{array}$ & $\begin{array}{r}39.07 \\
.24 \\
.79 \\
.03 \\
.84\end{array}$ & $\begin{array}{l}46.32 \star \\
<1.00 \\
<1.00 \\
<1.00\end{array}$ \\
\hline 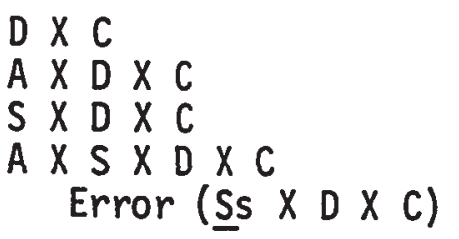 & $\begin{array}{r}1 \\
1 \\
1 \\
1 \\
20\end{array}$ & $\begin{array}{l}.07 \\
.63 \\
.07 \\
.29 \\
.62\end{array}$ & $\begin{array}{r}<1.00 \\
1.01 \\
<1.00 \\
<1.00\end{array}$ \\
\hline${ }^{*} p<.001$ & & & \\
\hline
\end{tabular}


TABLE 2

ANALYSIS OF VARIANCE OF RECOGNITION MEMORY SCORES

\begin{tabular}{|c|c|c|c|}
\hline Source & $d f$ & MS & $F$ \\
\hline $\begin{array}{l}\text { Age }(A) \\
\text { Sex }(S) \\
A \times S \\
\text { Error (SS) }\end{array}$ & $\begin{array}{r}1 \\
1 \\
1 \\
20\end{array}$ & $\begin{array}{l}2.34 \\
.01 \\
.09 \\
.56\end{array}$ & $\begin{array}{r}4.15 \\
<1.00 \\
<1.00\end{array}$ \\
\hline $\begin{array}{l}\text { Delay (D) } \\
A \times D \\
S \times D \\
A X S X D \\
\text { Error }(\underline{S S} \times D)\end{array}$ & $\begin{array}{r}1 \\
1 \\
1 \\
1 \\
20\end{array}$ & $\begin{array}{r}.26 \\
.09 \\
.51 \\
1.26 \\
.43\end{array}$ & $\begin{array}{r}<1.00 \\
<1.00 \\
1.18 \\
2.92\end{array}$ \\
\hline $\begin{array}{l}\text { Complexity }(C) \\
A \times C \\
S \times C \\
A \times S \times C \\
\text { Error }(S S \times C)\end{array}$ & $\begin{array}{r}1 \\
1 \\
1 \\
1 \\
20\end{array}$ & $\begin{array}{r}.26 \\
1.76 \\
.01 \\
.26 \\
.32\end{array}$ & $\begin{array}{l}4.00 \\
5.45^{\star} \\
<1.00 \\
<1.00\end{array}$ \\
\hline 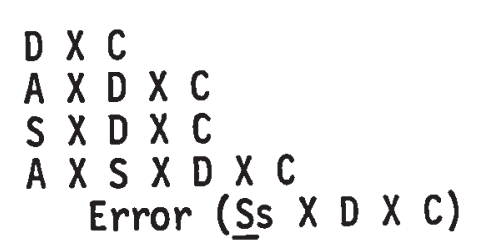 & $\begin{array}{r}1 \\
1 \\
1 \\
1 \\
20\end{array}$ & $\begin{array}{l}.26 \\
.09 \\
.26 \\
.01 \\
.61\end{array}$ & $\begin{array}{l}<1.00 \\
<1.00 \\
<1.00 \\
<1.00\end{array}$ \\
\hline
\end{tabular}


TABLE 3

ANALYSIS OF VARIANCE OF SELF-PACED RECALL VIEWING TIMES

\begin{tabular}{|c|c|c|c|}
\hline Source & $d f$ & MS & $F$ \\
\hline $\begin{array}{l}\text { Age (A) } \\
\text { Sex }(S) \\
A \times S \\
\text { Error ( } \underline{S} s)\end{array}$ & $\begin{array}{r}1 \\
1 \\
1 \\
20\end{array}$ & $\begin{array}{r}278.90 \\
117.01 \\
.59 \\
117.85\end{array}$ & $\begin{array}{r}2.36 \\
<1.00 \\
<1.00\end{array}$ \\
\hline $\begin{array}{l}\text { Delay }(D) \\
\text { A X D } \\
S \times X D \\
A \times S \times D \\
\text { Error }\left(\begin{array}{lll}S s & \times & D\end{array}\right)\end{array}$ & $\begin{array}{r}1 \\
1 \\
1 \\
1 \\
20\end{array}$ & $\begin{array}{r}70.60 \\
2.06 \\
1.72 \\
.83 \\
8.35\end{array}$ & $\begin{array}{l}8.45 * * \\
<1.00 \\
<1.00 \\
<1.00\end{array}$ \\
\hline $\begin{array}{l}\text { Complexity }(C) \\
A \times C \\
S \times C \\
A \times S \times C \\
\text { Error }(\underline{S} s \times C)\end{array}$ & $\begin{array}{r}1 \\
1 \\
1 \\
1 \\
20\end{array}$ & $\begin{array}{r}523.64 \\
20.74 \\
.81 \\
.01 \\
13.02\end{array}$ & $\begin{array}{l}40.20^{\dagger} \\
1.59 \\
<1.00 \\
<1.00\end{array}$ \\
\hline 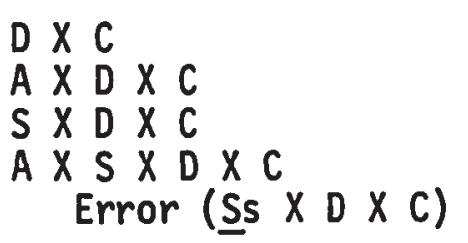 & $\begin{array}{r}1 \\
1 \\
1 \\
1 \\
20\end{array}$ & $\begin{array}{r}27.81 \\
11.41 \\
10.62 \\
.29 \\
5.81\end{array}$ & $\begin{array}{l}4.79^{\star} \\
1.96 \\
1.82 \\
<1.00\end{array}$ \\
\hline $\begin{array}{ll}* & p<.05 \\
* * & p<.01 \\
t & p<.001\end{array}$ & & & \\
\hline
\end{tabular}


TABLE 4

ANALYSIS OF VARIANCE OF SELF-PACED RECDGNITION VIEWING TIMES

\begin{tabular}{|c|c|c|c|}
\hline Source & $\mathrm{df}$ & MS & $F$ \\
\hline $\begin{array}{l}\text { Age }(A) \\
\text { Sex }(S) \\
A X S \\
\text { Error }(\underline{S} s)\end{array}$ & $\begin{array}{r}1 \\
1 \\
1 \\
20\end{array}$ & $\begin{array}{r}322.85 \\
35.22 \\
.56 \\
54.89\end{array}$ & $\begin{aligned} & 5.88^{*} \\
< & 1.00 \\
< & 1.00\end{aligned}$ \\
\hline $\begin{array}{l}\text { Delay }(D) \\
\text { A X D } \\
S \times X \text { D } \\
\text { A X S X D } \\
\text { Error }\left(\begin{array}{lll}S s & X & D\end{array}\right)\end{array}$ & $\begin{array}{r}1 \\
1 \\
1 \\
1 \\
20\end{array}$ & $\begin{array}{l}3.06 \\
1.39 \\
.01 \\
2.92 \\
2.40\end{array}$ & $\begin{array}{r}1.27 \\
<1.00 \\
<1.00 \\
1.21\end{array}$ \\
\hline $\begin{array}{l}\text { Complexity }(C) \\
\text { A } \times C \\
S \times C \\
A \times S \times C \\
\text { Error }(\underline{S s} \times C)\end{array}$ & $\begin{array}{r}1 \\
1 \\
1 \\
1 \\
20\end{array}$ & $\begin{array}{r}135.73 \\
.72 \\
4.06 \\
1.74 \\
5.51\end{array}$ & $\begin{array}{l}24.59 * \star \\
<1.00 \\
<1.00 \\
<1.00\end{array}$ \\
\hline 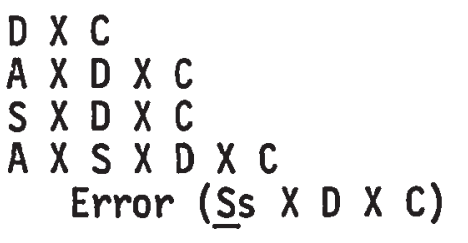 & $\begin{array}{r}1 \\
1 \\
1 \\
1 \\
20\end{array}$ & $\begin{array}{r}1.44 \\
3.74 \\
4.02 \\
4.79 \\
.92\end{array}$ & $\begin{array}{l}1.56 \\
4.06 \\
4.37^{*} \\
5.20^{*}\end{array}$ \\
\hline $\begin{array}{ll}* & p<.05 \\
* * & p<.001\end{array}$ & & & \\
\hline
\end{tabular}




\section{APPENDIX III}

\section{Experiment II $F$ tables.}




\section{TABLE 1}

ANALYSIS OF VARIANCE OF RECALL MEMORY SCORES

\begin{tabular}{|c|c|c|c|}
\hline Source & $\mathrm{df}$ & MS & $F$ \\
\hline $\begin{array}{l}\text { Age (A) } \\
\text { Sex (S) } \\
\text { Viewing time }(V) \\
A \times S \\
A \times V \\
A X V \\
S \times V \times V \\
A \times S \times V \\
\quad \text { Error }(\underline{S} s)\end{array}$ & $\begin{array}{r}1 \\
1 \\
2 \\
1 \\
2 \\
2 \\
2 \\
60\end{array}$ & $\begin{array}{r}48.96 \\
.03 \\
18.58 \\
.17 \\
26.07 \\
3.18 \\
.69 \\
3.03\end{array}$ & $\begin{array}{l}16.12^{\star \star} \\
<1.00 \\
6.11^{\star} \\
<1.00 \\
8.58^{\star \star} \\
1.04 \\
<1.00\end{array}$ \\
\hline 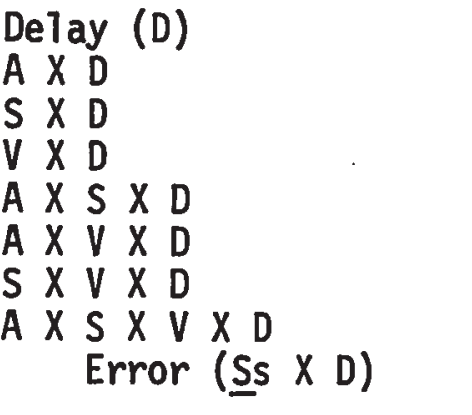 & $\begin{array}{r}1 \\
1 \\
1 \\
2 \\
1 \\
2 \\
2 \\
2 \\
60\end{array}$ & $\begin{array}{r}.11 \\
.01 \\
.07 \\
.53 \\
.65 \\
.04 \\
.58 \\
2.04 \\
.90\end{array}$ & $\begin{array}{l}<1.00 \\
<1.00 \\
<1.00 \\
<1.00 \\
<1.00 \\
<1.00 \\
<1.00 \\
2.26\end{array}$ \\
\hline 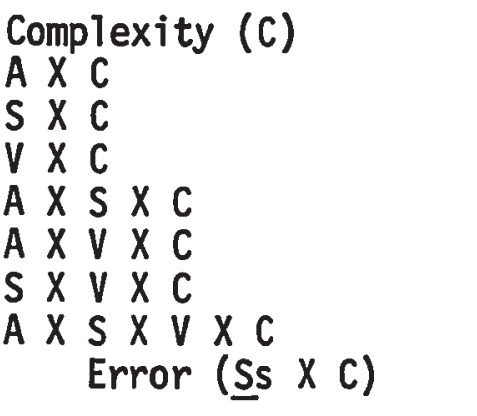 & $\begin{array}{r}1 \\
1 \\
1 \\
2 \\
1 \\
2 \\
2 \\
2 \\
60\end{array}$ & $\begin{array}{r}231.57 \\
1.35 \\
.15 \\
2.78 \\
3.83 \\
.92 \\
.50 \\
.44 \\
1.07\end{array}$ & $\begin{array}{l}215.40 \star \star \\
1.25 \\
<1.00 \\
2.58 \\
3.57 \\
<1.00 \\
<1.00 \\
<1.00\end{array}$ \\
\hline 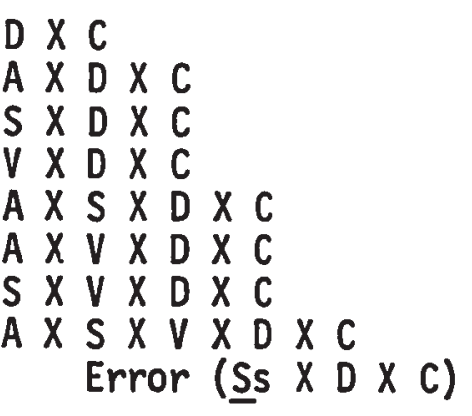 & $\begin{array}{r}1 \\
1 \\
1 \\
2 \\
1 \\
2 \\
2 \\
2 \\
60\end{array}$ & $\begin{array}{l}.56 \\
.01 \\
.70 \\
.58 \\
.11 \\
.71 \\
.82 \\
.16 \\
.49\end{array}$ & $\begin{array}{r}1.14 \\
<1.00 \\
1.42 \\
1.19 \\
<1.00 \\
1.45 \\
1.67 \\
<1.00\end{array}$ \\
\hline $\begin{array}{cl}* \star & p<.001 \\
* & p<.01\end{array}$ & & & \\
\hline
\end{tabular}


TABLE 2

ANALYSIS OF VARIANCE OF RECOGNITION MEMORY SCORES

\begin{tabular}{|c|c|c|c|}
\hline Source & $\mathrm{df}$ & MS & $F$ \\
\hline $\begin{array}{l}\text { Age (A) } \\
\text { Sex (S) } \\
\text { Viewing Time (V) } \\
A \times S \\
A \times V \\
S \times V \\
\text { A } X S \times V \\
\text { X Error }(\underline{S} s)\end{array}$ & $\begin{array}{r}1 \\
1 \\
2 \\
1 \\
2 \\
2 \\
2 \\
60\end{array}$ & $\begin{array}{l}6.12 \\
1.68 \\
3.21 \\
.22 \\
1.01 \\
3.33 \\
.52 \\
.78\end{array}$ & $\begin{array}{c}7.83^{\star *} \\
2.14 \\
4.10^{\star} \\
<1.00 \\
1.29 \\
4.26{ }^{\star} \\
<1.00\end{array}$ \\
\hline 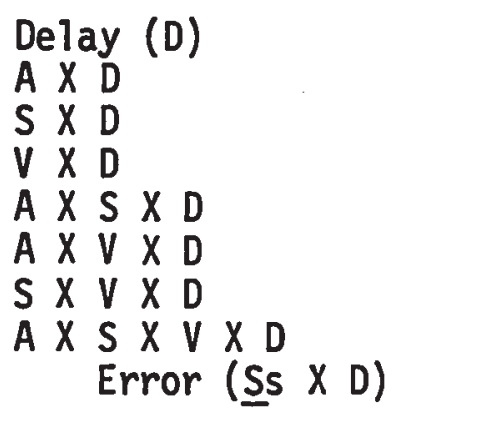 & $\begin{array}{r}1 \\
1 \\
1 \\
2 \\
1 \\
2 \\
2 \\
2 \\
60\end{array}$ & $\begin{array}{l}4.49 \\
4.01 \\
.01 \\
.09 \\
.05 \\
.17 \\
.02 \\
.46 \\
.38\end{array}$ & $\begin{array}{l}11.78 * * \\
10.50 * \star \\
<1.00 \\
<1.00 \\
<1.00 \\
<1.00 \\
<1.00 \\
1.20\end{array}$ \\
\hline 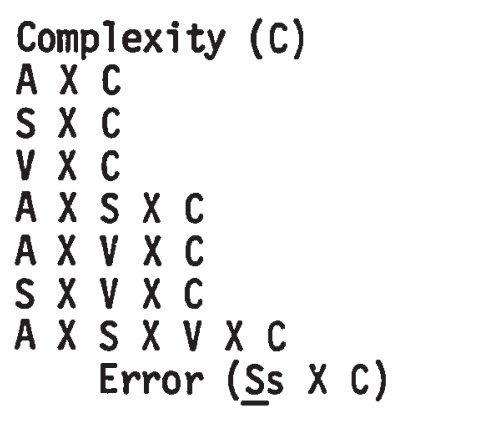 & $\begin{array}{r}1 \\
1 \\
1 \\
2 \\
1 \\
2 \\
2 \\
2 \\
60\end{array}$ & $\begin{array}{r}8.68 \\
.05 \\
.50 \\
.14 \\
1.12 \\
.01 \\
.22 \\
.07 \\
.41\end{array}$ & $\begin{array}{r}21.04^{\dagger} \\
<7.00 \\
1.21 \\
<7.00 \\
2.72 \\
<7.00 \\
<1.00 \\
<1.00\end{array}$ \\
\hline 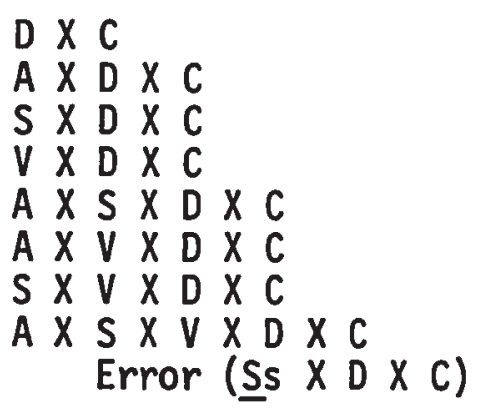 & $\begin{array}{r}1 \\
1 \\
1 \\
2 \\
1 \\
2 \\
2 \\
2 \\
60\end{array}$ & $\begin{array}{r}.13 \\
.01 \\
.88 \\
.28 \\
.34 \\
1.21 \\
.46 \\
1.14 \\
.29\end{array}$ & $\begin{array}{r}<1.00 \\
<1.00 \\
3.06 \\
<1.00 \\
1.19 \\
4.19{ }^{\star} \\
1.59 \\
3.95^{\star}\end{array}$ \\
\hline $\begin{array}{l}\star \star * \\
* \\
\star \\
+\end{array}$ & & & \\
\hline
\end{tabular}




\section{APPENDIX IV \\ Posteriori tests--Scheffe (Experiment I).}


$\begin{aligned} \text { CRITICAL VALUE (C.V.) } & =s \sqrt{V\left(\hat{\Psi}_{g}\right)} \\ & =\sqrt{(0-1) F_{a}}\end{aligned}$

$$
=\sqrt{(J-1) F_{\alpha}} \quad \sqrt{W_{g}\left(M S_{e}\right)}
$$

RECOGNITION MEMORY ( $X$ X interaction)

$$
\text { c.v. }=\sqrt{T(2.97)} \sqrt{\frac{1}{12}(.3229)}=.282
$$

SELF-PACED VIEWING TIME - RECALL (D X C interaction)

$$
\begin{aligned}
\text { C.V. } & =\sqrt{1(2.97)} \sqrt{\frac{1}{12}(.5805)}= \\
& =.379
\end{aligned}
$$

SELF-PACED VIEWING TIME - RECOGNITION

a) $D \times C \times S$ interaction

$$
\text { c.v. }=\sqrt{T(2.97)} \sqrt{\frac{1}{6}(.9199)}=.674
$$

b) $A \times S \times D \times C$ interaction

$$
\text { C.v. }=\sqrt{T(2.97)} \sqrt{\frac{1}{3}(.9199)}=.954
$$

$$
\text { NOTE: } \begin{aligned}
A & =\text { age } \\
C & =\text { complexity } \\
D & =\text { delay } \\
S & =\text { sex }
\end{aligned}
$$




\section{APPENDIX $V$}

Posteriori tests--Scheffe (Experiment II). 


$$
\begin{aligned}
\text { CRITICAL VALUE }\left(C . V_{.}\right) & =S \sqrt{V\left(\hat{\Psi}_{g}\right)} \\
& =\sqrt{(J-I) F_{\alpha}} \sqrt{W_{g}\left(M S_{e}\right)}
\end{aligned}
$$

\section{RECALL MEMORY}

a) $V$ main effect

$$
\text { C.V. }=\sqrt{2(2.39)} \sqrt{\frac{7}{48}(3.037)}=.549
$$

b) $A \times V$ interaction

$$
\text { c.v. }=\sqrt{2(2.39)} \sqrt{\frac{1}{24}(3.037)}=.777
$$

\section{RECOGNITION MEMORY}

a) $V$ main effect

$$
\text { C.V. }=\sqrt{2(2.39)} \sqrt{\frac{1}{48}(.7819)}=.279
$$

b) $S \times V$ interaction

$$
\text { C. } v .=\sqrt{2(2.39)} \sqrt{\frac{1}{24}(.7819)}=.394
$$

c) $A \times D$ interaction

$$
\text { C.V. }=\sqrt{1(2.84)} \sqrt{\frac{1(.3819)}{36}}=.173
$$

d) $A \times \vee \times D \times C$ interaction

$$
\text { C. } V .=\sqrt{2(2.39)} \sqrt{\frac{1}{6}(.2902)}=.480
$$

e) $A \times S \times V \times D \times C$ interaction

$$
\text { C.V. }=\sqrt{2(2.39)} \sqrt{\frac{1}{3}(.2902)}=.680
$$

$$
\text { NOTE: } \begin{aligned}
& A=\text { age } \\
& S=\text { sex } \\
& D=\text { delay } \\
& V=\text { viewing time } \\
& C=\text { complexity }
\end{aligned}
$$


APPENDIX VI

Analys is of demographic data (t-tests)

Experiments I and II 
COMPARISONS OF YOUNG AND OLDER SS WITH REGARD TO

AGE, VISUAL DISCRIMINATION TASK, QMI AND QWT

\section{Experiment I}

Table 1 (a)

AGE

\begin{tabular}{cccc}
\hline & $Y, F$ & $A, M$ & $A, F$ \\
$Y, M$ & .97 & $13.16^{*}$ & $19.45^{*}$ \\
$Y, F$ & & $13.35^{*}$ & $19.68^{*}$ \\
$A, M$ & & & .16
\end{tabular}

Table 1 (b)

VISUUAL DISCRIMINATION TASK

$\begin{array}{cccc} & Y, F & A, M & A, F \\ Y, M & 0 & .12 & .05 \\ Y, F & & .12 & .05 \\ A, M & & & .06\end{array}$

Tabie 1 (c)

QMI

\begin{tabular}{rrrr}
\hline & $Y, F$ & $A, M$ & $A, F$ \\
$Y, M$ & .35 & .11 & .92 \\
$Y, F$ & & .46 & .44 \\
$A, M$ & & & 1.07
\end{tabular}

Table l (d)

QWT

\begin{tabular}{lrrr}
\hline & $Y, F$ & $A, M$ & $A, F$ \\
$Y, M$ & .21 & 1.20 & 1.83 \\
$Y, F$ & & .86 & 1.37 \\
$A, M$ & & & .49
\end{tabular}

$* p<.01$ 
Experiment II

Table 2 (a)

AGE

\begin{tabular}{cccc}
\hline & $Y, F$ & $A, M$ & $A, F$ \\
$Y, M$ & 1.16 & $33.03^{*}$ & $32.86^{*}$ \\
$Y, F$ & & $32.13^{*}$ & $31.97^{*}$ \\
$A, M$ & & & .08
\end{tabular}

Table 2 (b)

. . VISUAL DISCRIMINATION TASK

$\begin{array}{cccc} & Y, F & A, M & A, F \\ Y, M & .01 & .157 & .02 \\ Y, F & & .23 & .04 \\ A, M & & & .14\end{array}$

Table 2 (c)

QMI

$\begin{array}{cccc} & Y, F & A, M & A, F \\ Y, M & 1.61 & .40 & 1.22 \\ Y, F & & 2.14 & 3.34^{*} \\ A, M & & & .82\end{array}$

Table 2 (d)

QWT

$\begin{array}{lccc} & Y, F & A, M & A, F \\ Y, M & .02 & 1.20 & .43 \\ Y, F & & 1.41 & .51 \\ A, M & & & .76 \\ & & & \\ * \quad p<.01 & & \end{array}$


APPENDIX VII

Correlational analyses (Experiments I and II). 
TABLE 1.

Intercorrelations between STM performance and other subject characteristics (Experiment I)*

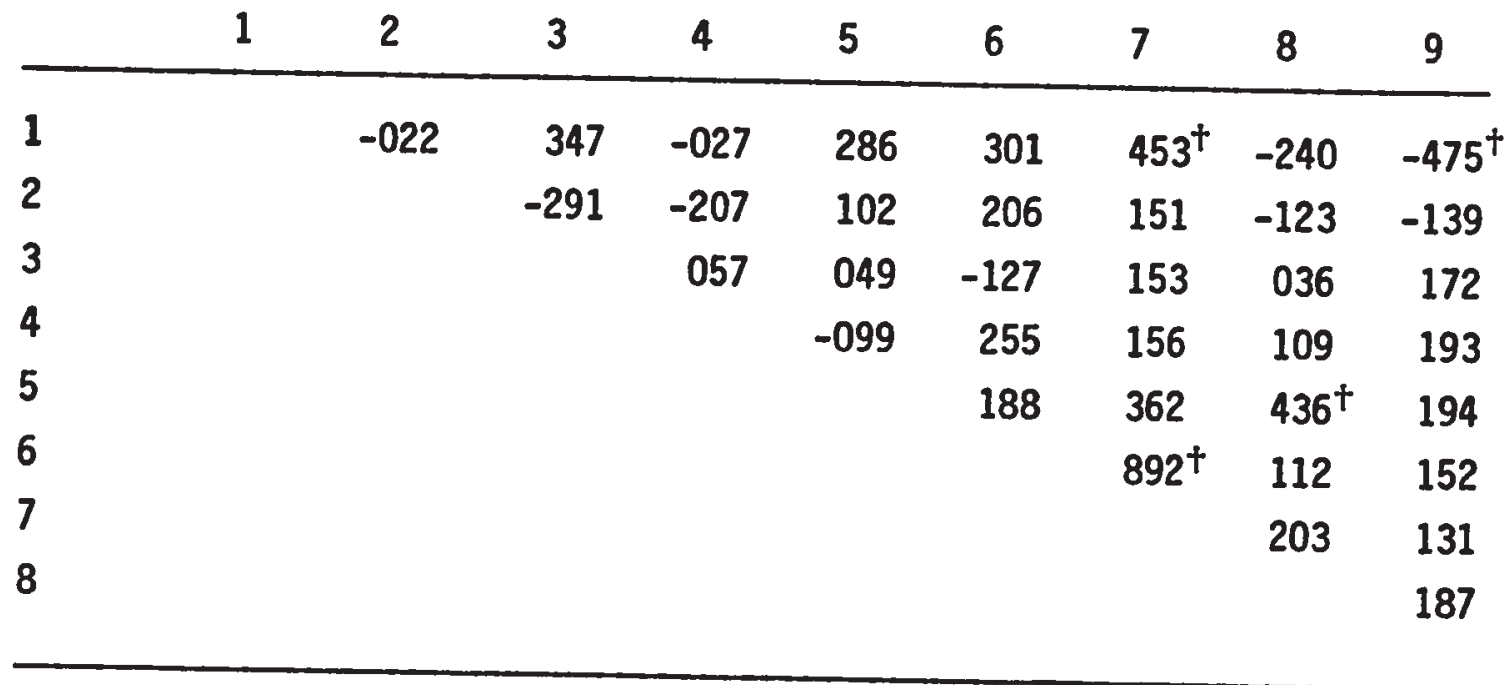

* Decimals have been omitted

$$
\begin{aligned}
& 1 \text { - Age } \\
& 2 \text { - Sex } \\
& 3 \text { - Visual Discrimination Task } \\
& 4 \text { - QMI } \\
& 5 \text { - QWT } \\
& 6 \text { - Time - Recall } \\
& 7 \text { - Time - Recognition } \\
& 8 \text { - Recall } \\
& 9 \text { - Recognition }
\end{aligned}
$$$$
+p<.05
$$ 
TABLE 2.

Intercorrelations between STM performance and other subject characteristics ( 3 seconds viewing time).*

\begin{tabular}{|c|c|c|c|c|c|c|c|c|c|c|}
\hline 1 & 2 & 3 & 4 & 5 & 6 & 7 & 8 & 9 & 10 & 11 \\
\hline 1 & 019 & -199 & 150 & 125 & 6824 & -287 & -189 & $-592^{\dagger}$ & $-729^{\dagger}$ & $-486^{\dagger}$ \\
\hline 2 & & $442^{+}$ & 091 & -046 & 000 & 102 & 353 & -086 & 095 & 166 \\
\hline 3 & & & 356 & -050 & -212 & 331 & -096 & 079 & $402^{\dagger}$ & 129 \\
\hline 4 & & & & 250 & 203 & 041 & -216 & -370 & -223 & -110 \\
\hline 5 & & & & & 072 & -142 & -109 & -066 & -127 & 073 \\
\hline 6 & & & & & & -017 & -119 & $-654^{+}$ & $-528^{\dagger}$ & -246 \\
\hline 7 & & & & & & & -290 & -185 & 334 & 183 \\
\hline 8 & & & & & & & & 182 & 209 & 117 \\
\hline 9 & & & & & & & & & $479^{t}$ & 269 \\
\hline 10 & & & & & & & & & & $473^{\dagger}$ \\
\hline
\end{tabular}

* Decimals have been omitted

1 - Age

2 - Sex

$+p<.05$

3 - Visual Discrimination Task

4 - OMI

5 - QWT

6 - Counting

7 - Imagery

8 - Similarity

9 - Other

10 - Recall

11 - Recognition 
TABLE 3.

Intercorrelations between STM performance and other subject characteristics ( 6 seconds viewing time).*

\begin{tabular}{|c|c|c|c|c|c|c|c|c|c|c|}
\hline 1 & 2 & 3 & 4 & 5 & 6 & 7 & 8 & 9 & 10 & 11 \\
\hline 1 & -002 & -389 & $-462^{\dagger}$ & 126 & 117 & 100 & -326 & -050 & -350 & -336 \\
\hline 2 & & -276 & 030 & -422 & 176 & 275 & 000 & -192 & -151 & $-505^{\dagger}$ \\
\hline 3 & & & 026 & 261 & -351 & -197 & 159 & -031 & 331 & 114 \\
\hline 4 & & & & 140 & -180 & -048 & 289 & -052 & 118 & 393 \\
\hline 5 & & & & & -185 & 024 & -303 & -140 & 038 & $505^{\dagger}$ \\
\hline 6 & & & & & & -324 & 000 & -204 & -044 & -132 \\
\hline 7 & & & & & & & $-688^{t}$ & 052 & -143 & -121 \\
\hline 8 & & & & & & & & -111 & 290 & 054 \\
\hline 9 & & & & & & & & & -193 & 291 \\
\hline 10 & & & & & & & & & & 257 \\
\hline
\end{tabular}

* Decimals have been omitted

1 - Age

2 - Sex

$+p<.05$

3 - Visual Discrimination Task

4 - QMI

5 - QWT

6 - Counting

7 - Imagery

8 - Similarity

9 - Other

10 - Recall

11 - Recognition 
TABLE 4.

Intercorrelations between STM performance and other subject characteristics (12 seconds viewing time).*

\begin{tabular}{|c|c|c|c|c|c|c|c|c|c|c|}
\hline 1 & 2 & 3 & 4 & 5 & 6 & 7 & 8 & 9 & 10 & 11 \\
\hline 1 & -004 & -350 & -381 & 221 & -199 & 285 & -193 & -066 & 166 & -230 \\
\hline 2 & & 322 & 117 & 147 & 086 & 192 & -169 & $-458^{\dagger}$ & -340 & -186 \\
\hline 3 & & & 075 & -077 & $416^{\dagger}$ & 079 & 163 & -063 & -108 & 171 \\
\hline 4 & & & & 031 & -013 & -150 & 156 & 255 & -173 & -179 \\
\hline 5 & & & & & -223 & -088 & 067 & 302 & -095 & 116 \\
\hline 6 & & & & & & 049 & -305 & -260 & $-462^{\dagger}$ & 000 \\
\hline 7 & & & & & & & -292 & 052 & 102 & -214 \\
\hline 8 & & & & & & & & 170 & 257 & 104 \\
\hline 9 & & & & & & & & & $456^{\dagger}$ & 022 \\
\hline 10 & & & & & & & & & & 070 \\
\hline
\end{tabular}

* Decimals have been omitted

1 - Age

2 - Sex

$+p<.05$

3 - Visual Discrimination Task

4 - QMI

5 - QWT

6 - Counting

7 - Imagery

8 - Similarity

9 - Other

10 - Recall

11 - Recognition 


\section{TABLE 5.}

Intercorrelations between STM performance and other subject characteristics (combined for $72 \underline{\mathrm{S}} \mathrm{s}$ ).*

\begin{tabular}{|c|c|c|c|c|c|c|c|c|c|c|}
\hline 1 & 2 & 3 & 4 & 5 & 6 & 7 & 8 & 9 & 10 & 11 \\
\hline 1 & 004 & -288 & -245 & 158 & 201 & 038 & -228 & -244 & $-368^{\dagger}$ & $-341^{+}$ \\
\hline 2 & & 211 & 073 & -054 & 084 & 192 & 058 & -241 & -055 & -173 \\
\hline 3 & & & 155 & -015 & -031 & 105 & 049 & 000 & 285 & 142 \\
\hline 4 & & & & 145 & -035 & -058 & 083 & -056 & 144 & 068 \\
\hline 5 & & & & & -146 & -073 & -037 & 081 & -139 & 089 \\
\hline 6 & & & & & & -080 & -138 & $-397^{\dagger}$ & -276 & -078 \\
\hline 7 & & & & & & & $-408^{t}$ & -034 & 162 & -028 \\
\hline 8 & & & & & & & & 085 & 203 & 053 \\
\hline 9 & & & & & & & & & 261 & 180 \\
\hline 10 & & & & & & & & & & $371^{\dagger}$ \\
\hline
\end{tabular}

* Decimals have been omitted

1 - Age

2 - Sex

3 - Visual Discrimination Task

$+p<.01$

4 - QMI

5 - QWT

6 - Counting

7 - Imagery

8 - Similarity

9 - Other

10 - Recall

11 - Recognition 
TABLE 6

Correlations between age and memory scores after partialling out the effects of "counting"

$$
R_{12.3}=\frac{r_{12}-r_{13} r_{23}}{\sqrt{1-r_{13}{ }^{2}} \sqrt{1-r_{23}{ }^{2}}}
$$

Recal1 Memory

$$
R_{12.3}=\frac{-.729-(.682)(-.528)}{\sqrt{1-(.682)^{2}} \sqrt{1-(-.528)^{2}}}=-.59
$$

Recognition memory

$$
R_{12.3}=\frac{-.486-(.682)(-.246)}{\sqrt{1-(.682)^{2}} \sqrt{1-(-.246)^{2}}}=-.44
$$




\section{APPENDIX VIII}

Post-experimental inquiry (Exp. II) 


\section{QUESTIONNAIRE}

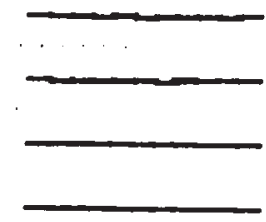

1. How did you go about trying to remember the patterns on the slides?

2. Inquiry

3. Did you think that on the whole the slide was on for:

a. too short a time

b. just long enough

c. too long a time 
APPENDIX IX

Post-experimental inquiry results (Exp. II) 


\section{TABLE 1}

Coding methods used in Experiment II

Each subject could use more than one method.

Counting Imagery Similarity to Other Total other objects

\begin{tabular}{|c|c|c|c|c|c|c|}
\hline Young & 1 & 4 & 9 & 8 & 22 & \multirow{2}{*}{$\begin{array}{l}3 \text { sec. } \\
\text { viewing time }\end{array}$} \\
\hline 01der & 9 & 1 & 7 & 1. & 18 & \\
\hline Young & 7 & 2 & 12 & 3 & 24 & \multirow{2}{*}{$\begin{array}{l}6 \text { sec. } \\
\text { viewing time }\end{array}$} \\
\hline 01 der. & 9 & 4 & 7. & 3 & 23 & \\
\hline Young & 9 & 2 & 9 & 4 & 24 & \multirow{2}{*}{$\begin{array}{l}12 \mathrm{sec} . \\
\text { viewing time }\end{array}$} \\
\hline 01der & 6 & 4 & 6 & 2 & 18 & \\
\hline
\end{tabular}


APPENDIX $X$

Experiment I raw scores. 
DATA CODE
1) Subject number
2) Age
3) $\operatorname{Sex}($ Male $=1$, Female $=2)$
4) Visual discrimination task score
5) QMI score
6) QWT score
7) Order of presentation: 1 -- recall first, no delay first 2 -- recall first, delay first 3 -- recognition first, no delay first 4 -- recognition first, delay first

8) Recall task (delay, simple)

9) " " (delay, complex)

10) " (no delay, simple)

11) " (no delay, complex)

12) Recognition task (delay, simple)

13) " (delay, compiex)

14) " (no delay, simple)

15) " (no delay, complex)

16) Self paced viewing time -- recall task (delay, simple)
17) " " " " (delay, complex)
18) " " " " (no delay, simple)
19) " " " " (no delay, complex)

20) Self paced viewing time -- recognition task (delay, simple)
21)
22)
23)

24) Educational level (number of years in school) 


\section{TABLE 1}

Raw Scores. Experiment I

1) $\begin{array}{llllllllllll}24 & 1 & 84 & 44 & 74 & 77 & 28 & 40 & 43 & 42 & 2 & 39\end{array}$

2) $\begin{array}{llllllllllll}56 & 52 & 62 & 54 & 52 & 62 & 17 & 21 & 22 & 19 & 22 & 20\end{array}$

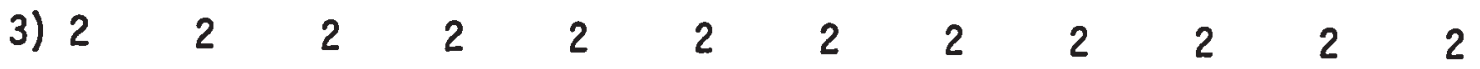

4) $\begin{array}{llllllllllll}7 & 7 & 7 & 6 & 6 & 7 & 7 & 7 & 6 & 6 & 6 & 5\end{array}$

5) $\begin{array}{llllllllllll}81 & 111 & 83 & 93 & 35 & 60 & 82 & 72 & 50 & 57 & 139 & 109\end{array}$

6) $\begin{array}{llllllllllll}81 & 88 & 94 & 89 & 87 & 67 & 84 & 70 & 64 & 87 & 87 & 65\end{array}$

7) $2 \quad \begin{array}{lllllllllll}2 & 3 & 1 & 4 & 2 & 1 & 4 & 2 & 1 & 2 & 4\end{array}$

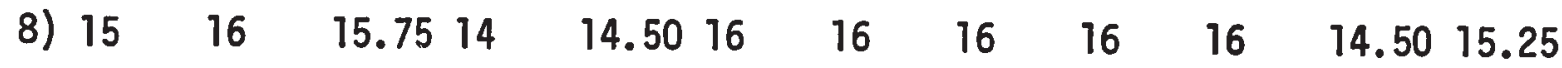

9) $12.75 \quad 14.50 \quad 14.75 \quad 15.25 \quad 11.25 \quad 15.25 \quad 16 \quad 14.50 \quad 12.25 \quad 15.50 \quad 14 \quad 11.50$

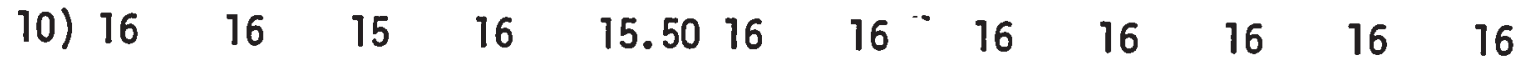
11) $16 \quad 13.75 \quad 14.50 \quad 12.25 \quad 12.25 \quad 15 \quad 15.25 \quad 15.75 \quad 14 \quad 15 \quad 14.50 \quad 14.75$ 12) $4 \quad 4 \quad 4 \quad 2 \quad \begin{array}{lllllllll} & 4 & 3 & 3 & 4 & 4 & 4 & 4 & 4\end{array}$

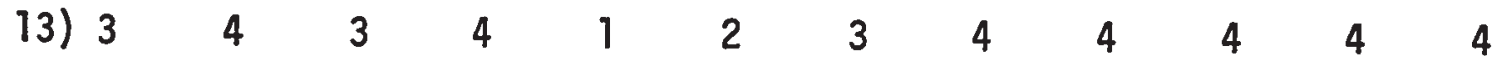
14) $\begin{array}{llllllllllll}4 & 4 & 3 & 4 & 4 & 3 & 4 & 2 & 3 & 4 & 4 & 3\end{array}$

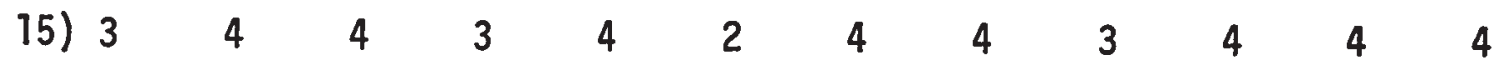

16) $10.70 \quad 11.80 \quad 13.50 \quad 9.40 \quad 10.10 \quad 16.25 \quad 10.702 .50 \quad 2.60 \quad 4.20 \quad 13.30 \quad 27.90$ 17) $12 \quad 20.50 \quad 17.70 \quad 10.7012 .90 \quad 16.40 \quad 13.50 \quad 2.80 \quad 2.90 \quad 5.30 \quad 13.90 \quad 31.30$

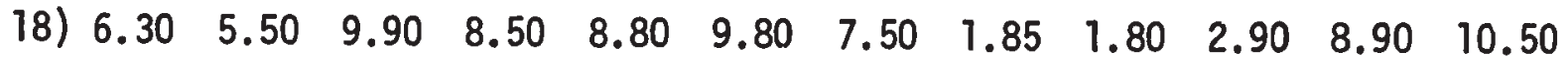

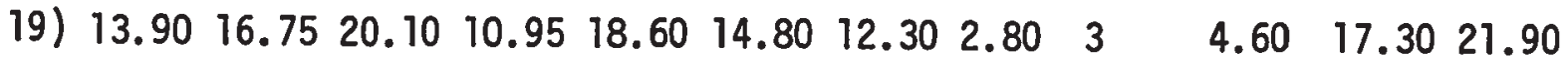

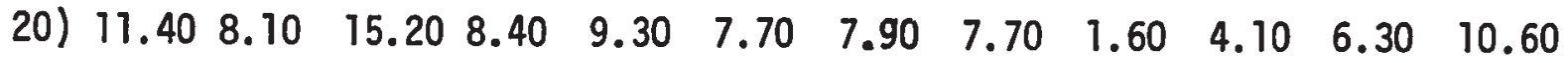

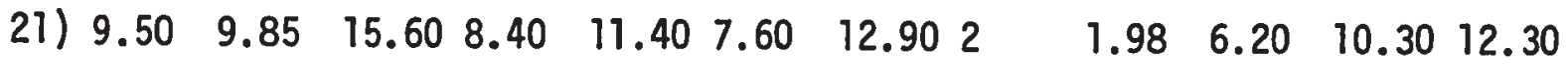

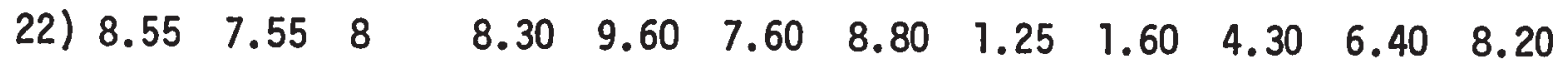

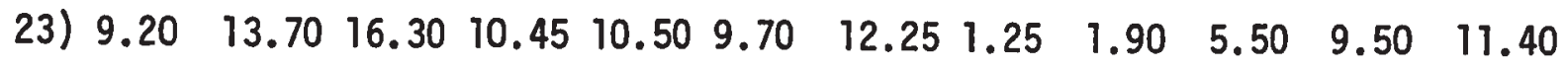
24) $\begin{array}{llllllllllll}10 & 12 & 15 & 10 & 12 & 8 & 13 & 15 & 12 & 14 & 15 & 15\end{array}$ 


\section{TABLE 2}

Raw Scores. Experiment I

1) $\begin{array}{llllllllllll}93 & 86 & 69 & 85 & 88 & 49 & 66 & 92 & 11 & 29 & 52 & 64\end{array}$ 2) $\begin{array}{llllllllllll}64 & 61 & 55 & 62 & 53 & 47 & 20 & 22 & 21 & 24 & 20 & 20\end{array}$

3) $\begin{array}{llllllllllll}1 & 1 & 1 & 1 & 1 & 1 & 1 & 1 & 1 & 1 & 1 & 1\end{array}$

4) $\begin{array}{llllllllllll}7 & 7 & 7 & 7 & 7 & 6 & 7 & 6 & 6 & 7 & 7 & 7\end{array}$

5) $\begin{array}{llllllllllll}107 & 111 & 54 & 111 & 85 & 86 & 95 & 107 & 64 & 61 & 96 & 128\end{array}$

6) $\begin{array}{llllllllllll}66 & 86 & 84 & 72 & 94 & 87 & 65 & 69 & 86 & 83 & 73 & 74\end{array}$

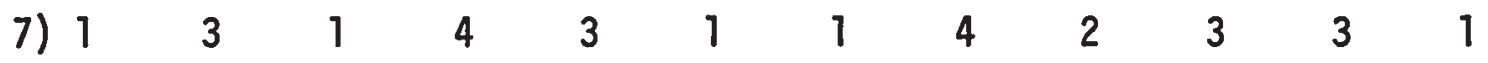

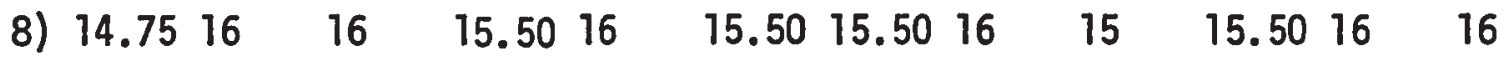

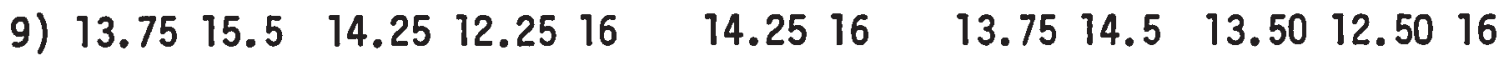

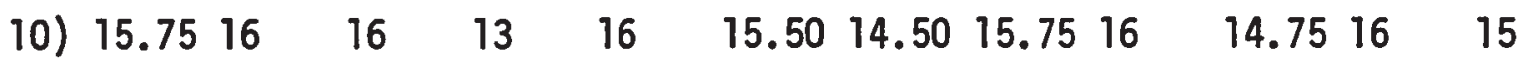

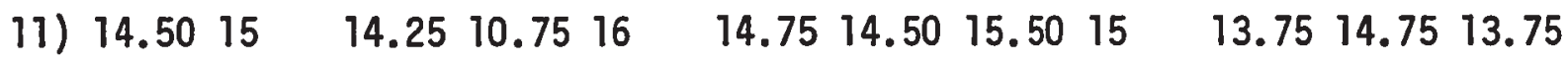

12) $\begin{array}{llllllllllll}3 & 4 & 4 & 3 & 4 & 4 & 4 & 4 & 4 & 4 & 3 & 3\end{array}$

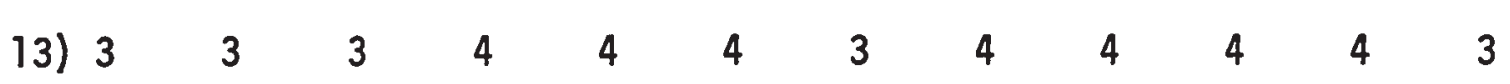

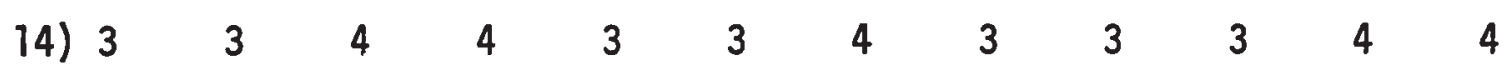

15) $1 \quad 3 \quad 4 \quad 4 \quad 2 \quad \begin{array}{lllllllll}1 & 3 & 4 & 4 & 4 & 4 & 3 & 3 & 4\end{array}$

16) $\begin{array}{llllllllllll}17.60 & 5 & 7 & 3.90 & 15 & 4 & 6.60 & 1.98 & 8.90 & 2.20 & 5.10 & 9.75\end{array}$

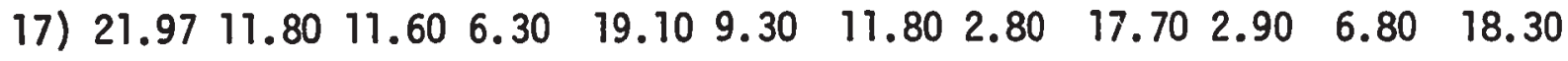

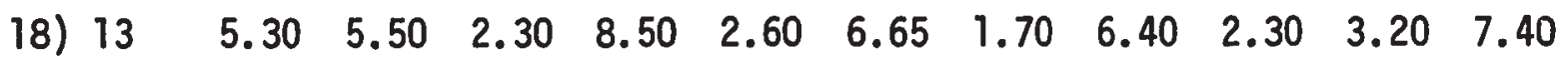

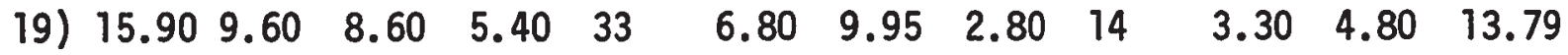

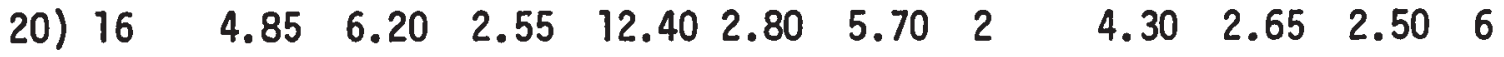

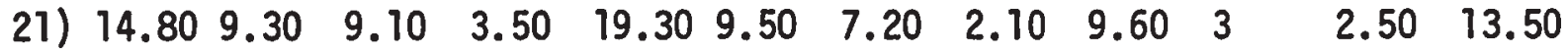

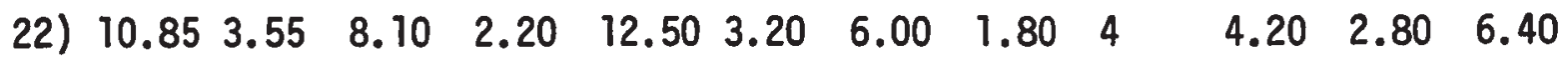

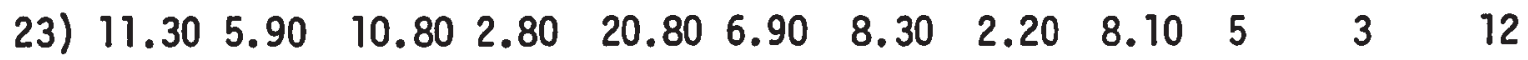
24) $\begin{array}{llllllllllll}7 & 7 & 8 & 12 & 15 & 11 & 12 & 17 & 12 & 19 & 12 & 12\end{array}$ 
APPENDIX $X I$

Raw data (Experiment II). 
DATA CODE
1) Subject number
2) Age
3) $\quad$ Sex $($ Male $=1$, Female $=2)$
4) Visual discrimination task score
5) QMI score
6) QWT score
7) Counting ( $\mathrm{No}_{\mathrm{O}}=1$, Yes $=2$ )
8) Imagery (No $=1$, Yes $=2$ )
9) Similarity to other objects ( No $=1$, Yes $=2$ )
10) Other methods (No $=1$, Yes $=2$ )
11) Order of presentation: 1 -- recall first, no delay first 2 -- recall first, delay first
3 -- recognition first, no delay first
4 -- recognition first, delay first

12) Recall task (delay, simple)

13) " (delay, complex)

14) " (no delay, simple)

15) " " (no delay, complex)

16) Recognition task (delay, simple)

17) " " (delay, complex)

18) " (no delay, simple)

19) " (no delay, complex)

20) Educational level 
TABLE 1

Raw Scores. Experiment II

(1;2 sec. viewing time)

1) $\begin{array}{llllllllllll}48 & 70 & 87 & 53 & 63 & 23 & 114 & 115 & 113 & 110 & 112 & 75\end{array}$

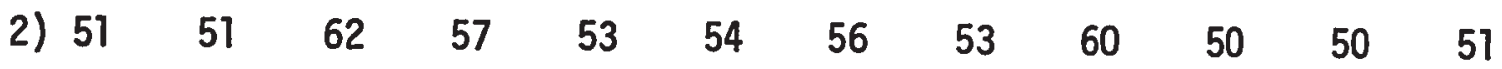

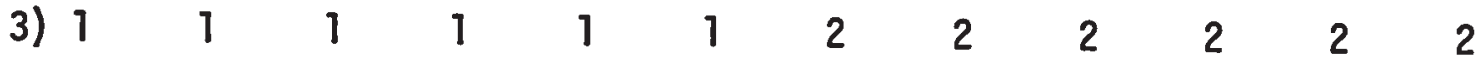
4) $\begin{array}{llllllllllll}5 & 6 & 7 & 7 & 4 & 4 & 6 & 7 & 7 & 7 & 6 & 6\end{array}$ 5) $\begin{array}{llllllllllll}71 & 79 & 76 & 59 & 82 & 77 & 48 & 54 & 65 & 77 & 95 & 60\end{array}$ 6) $\begin{array}{llllllllllll}71 & 72 & 68 & 70 & 96 & 77 & 42 & 88 & 86 & 96 & 81 & 83\end{array}$

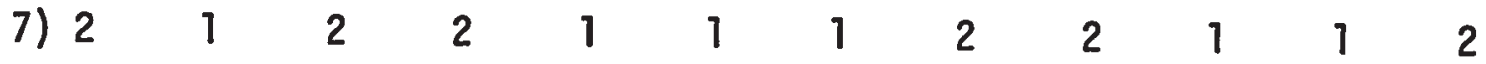

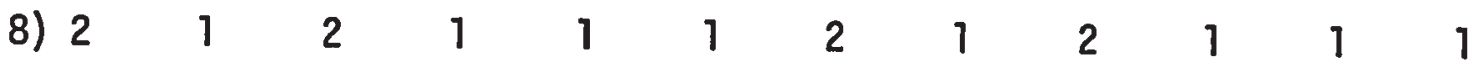

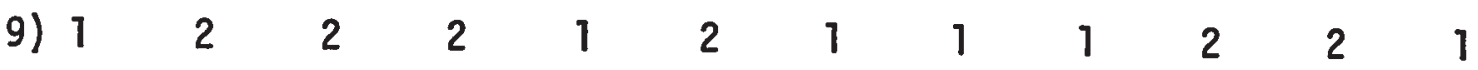

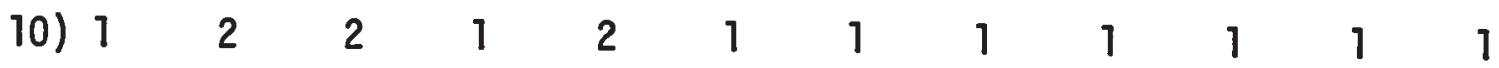

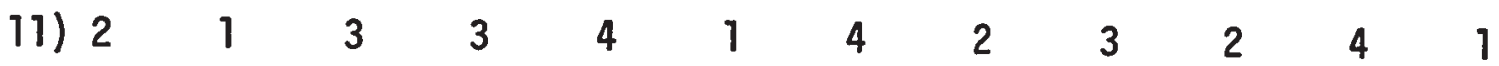

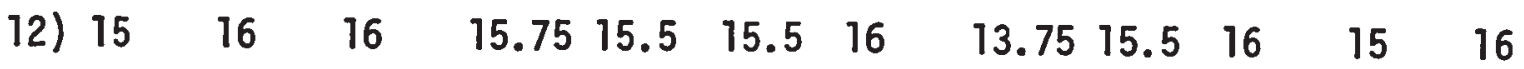

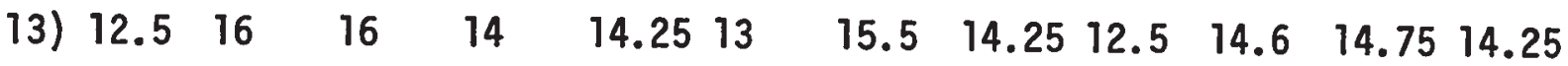
14) $\begin{array}{llllllllllll}16 & 16 & 16 & 16 & 15 & 15.5 & 16 & 14.75 & 16 & 16 & 15.5 & 16\end{array}$

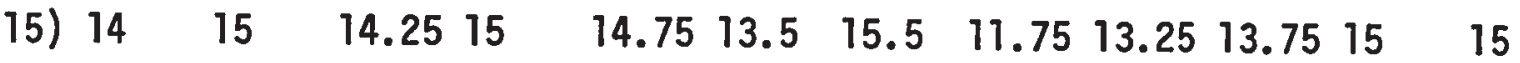
16) $4 \quad 4 \quad 3 \quad \begin{array}{llllllllll} & 4 & 4 & 4 & 3 & 4 & 4 & 4 & 4 & 4\end{array}$

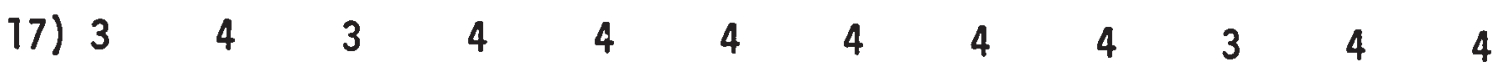
18) $4 \quad 4 \quad 4 \quad 4 \quad 4 \quad 4 \quad \begin{array}{llllllll}3 & 3 & 3 & 4 & 4 & 4 & 3\end{array}$

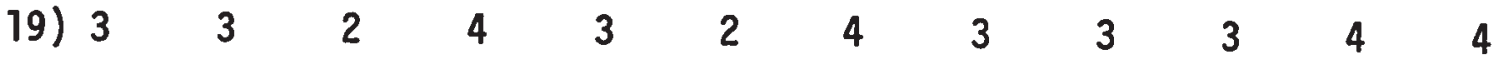
20) $\begin{array}{llllllllllll}7 & 11 & 12 & 12 & 12 & 12 & 12 & 11 & 11 & 10 & 16 & 10\end{array}$ 
TABLE 2

Raw Scores. Experiment II

(12 sec. viewing time)

1) $\begin{array}{llllllllllll}106 & 107 & 105 & 68 & 57 & 59 & 101 & 19 & 100 & 8 & 102 & 32\end{array}$

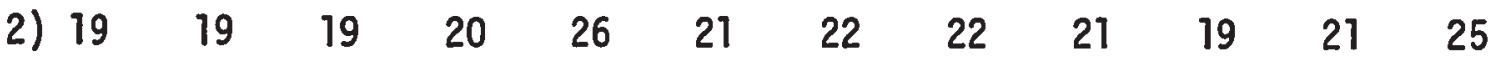

3) $\begin{array}{llllllllllll}1 & 1 & 1 & 1 & 1 & 1 & 2 & 2 & 2 & 2 & 2 & 2\end{array}$

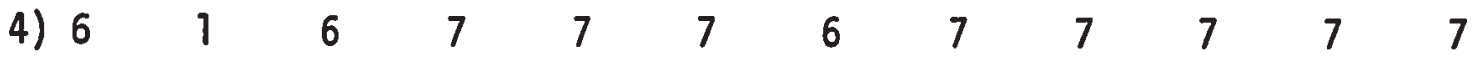

5) $\begin{array}{llllllllllll}58 & 80 & 63 & 72 & 53 & 121 & 94 & 80 & 83 & 103 & 89 & 88\end{array}$

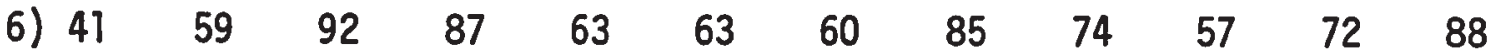

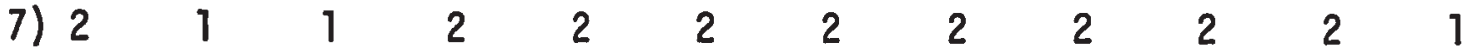

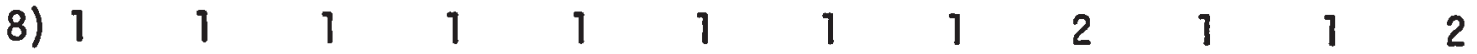

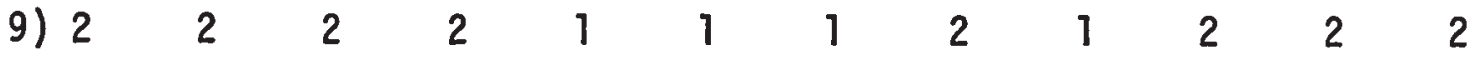

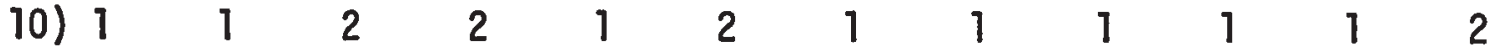

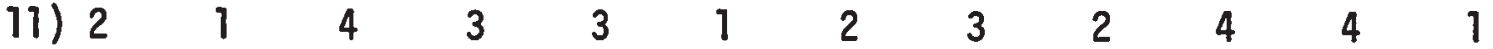

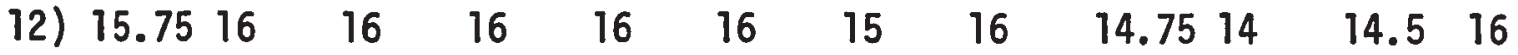

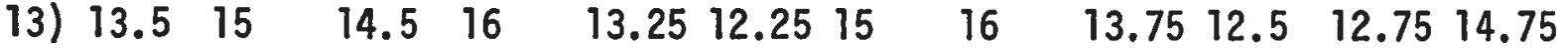

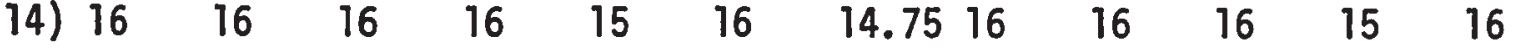

15) $\begin{array}{llllllllllll}14.75 & 15 & 16 & 15.5 & 11.5 & 13.5 & 14 & 15.25 & 13.75 & 15 & 12.5 & 13.25\end{array}$

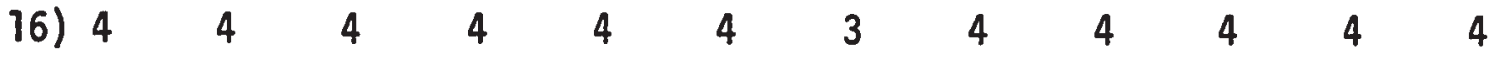
17) $\begin{array}{llllllllllll}4 & 3 & 4 & 4 & 3 & 3 & 4 & 4 & 4 & 3 & 2 & 3\end{array}$ 18) $4 \quad 4 \quad 4 \quad 4 \quad 4 \quad 4 \quad \begin{array}{llllllll}4 & 2 & 4 & 4 & 4 & 4 & 3\end{array}$

19) $4 \quad 4 \quad 4 \quad 4 \quad 4 \quad 2 \quad \begin{array}{llllllll}4 & 2 & 4 & 4 & 4 & 3 & 4\end{array}$ 20) $\begin{array}{llllllllllll}11 & 12 & 14 & 14 & 12 & 11 & 11 & 12 & 12 & 10 & 10 & 12\end{array}$ 


\section{TABLE 3}

Raw Scores. Experiment II

(6 sec. viewing time)

1) $\begin{array}{llllllllllll}67 & 95 & 90 & 99 & 79 & 12 & 116 & 72 & 71 & 78 & 37 & 98\end{array}$ 2) $\begin{array}{llllllllllll}54 & 61 & 60 & 60 & 52 & 50 & 58 & 54 & 55 & 48 & 62 & 56\end{array}$ 3) $\begin{array}{llllllllllll}1 & 1 & 1 & 1 & 1 & 1 & 2 & 2 & 2 & 2 & 2 & 2\end{array}$

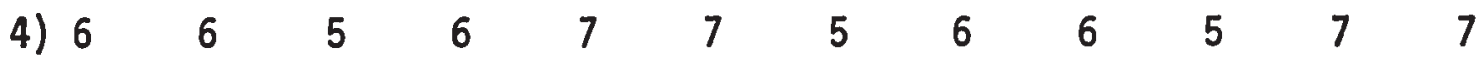
5) $\begin{array}{llllllllllll}66 & 53 & 110 & 80 & 51 & 38 & 68 & 66 & 49 & 68 & 80 & 43\end{array}$ 6) $\begin{array}{llllllllllll}72 & 90 & 82 & 86 & 92 & 93 & 72 & 70 & 85 & 84 & 82 & 74\end{array}$ 7) $2 \quad \begin{array}{lllllllllll}1 & 2 & 2 & 1 & 2 & 2 & 2 & 2 & 2 & 1 & 2\end{array}$

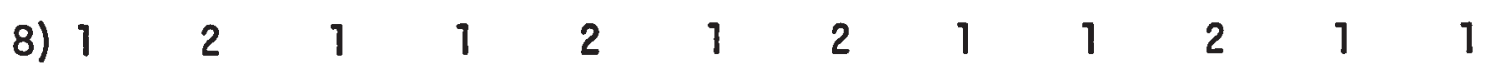

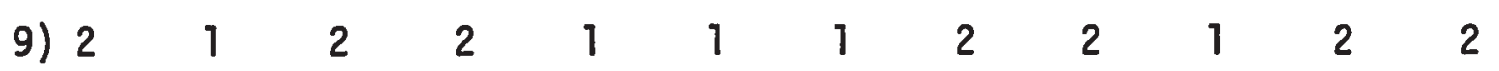
10) $\begin{array}{llllllllllll}1 & 2 & 1 & 1 & 1 & 1 & 1 & 2 & 1 & 2 & 1 & 1\end{array}$ 11) $4 \quad \begin{array}{lllllllllll}4 & 3 & 3 & 2 & 1 & 4 & 2 & 4 & 2 & 3 & 1\end{array}$ 12) $\begin{array}{llllllllllll}16 & 16 & 16 & 16 & 16 & 16 & 15.5 & 15.5 & 16 & 14.5 & 14.75 & 16\end{array}$

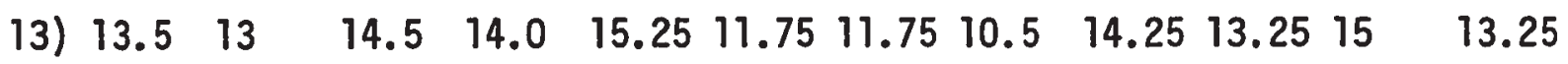

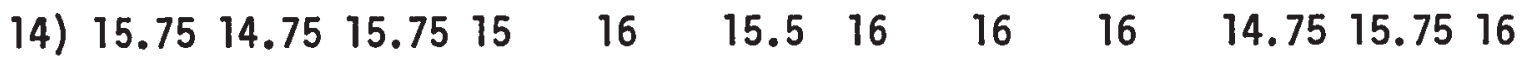

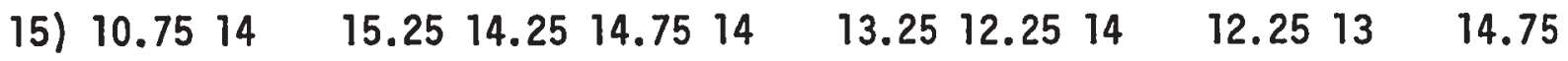

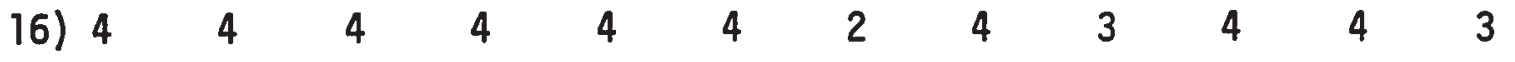

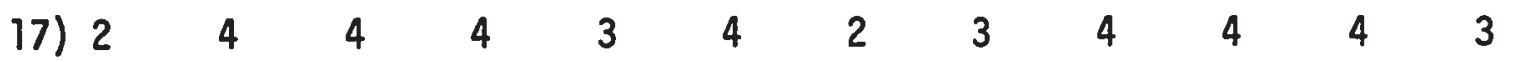

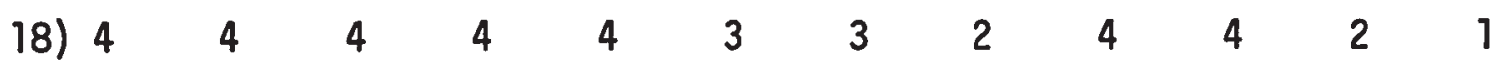

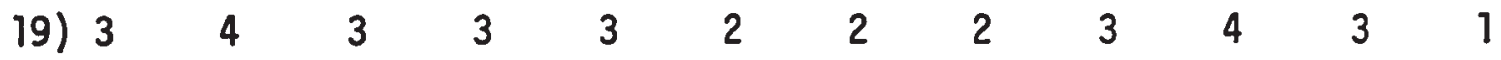
20) $\begin{array}{llllllllllll}7 & 12 & 12 & 15 & 12 & 12 & 15 & 9 & 12 & 12 & 11 & 11\end{array}$ 
TABLE 4

Raw Scores. Experiment II

(6 sec. viewing time)

1) $\begin{array}{llllllllllll}109 & 56 & 58 & 82 & 80 & 104 & 108 & 33 & 5 & 36 & 46 & 17\end{array}$

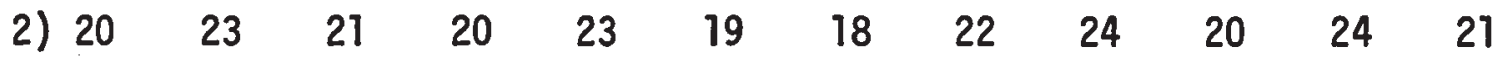

3) $\begin{array}{llllllllllll}1 & 1 & 1 & 1 & 1 & 1 & 2 & 2 & 2 & 2 & 2 & 2\end{array}$

4) $\begin{array}{llllllllllll}7 & 7 & 7 & 7 & 7 & 7 & 7 & 7 & 6 & 6 & 7 & 5\end{array}$

5) $\begin{array}{llllllllllll}50 & 94 & 76 & 124 & 83 & 86 & 86 & 111 & 56 & 92 & 117 & 92\end{array}$

6) $\begin{array}{llllllllllll}60 & 85 & 91 & 88 & 95 & 79 & 76 & 81 & 65 & 78 & 83 & 70\end{array}$

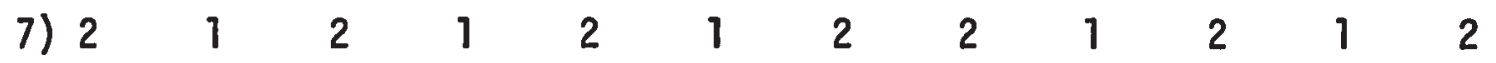

8) $\begin{array}{llllllllllll}1 & 1 & 1 & 1 & 1 & 1 & 1 & 2 & 2 & 1 & 2 & 1\end{array}$

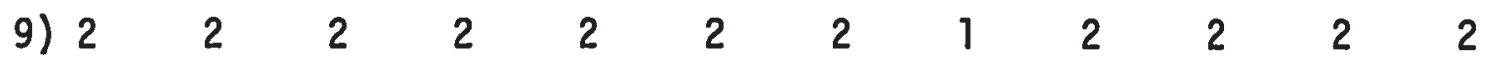

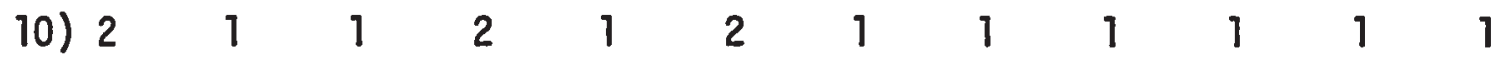

11) $\begin{array}{llllllllllll}4 & 1 & 2 & 3 & 1 & 3 & 4 & 2 & 2 & 4 & 1 & 3\end{array}$

12) $\begin{array}{llllllllllll}16 & 16 & 16 & 16 & 16 & 16 & 15.5 & 16 & 16 & 16 & 16 & 16\end{array}$

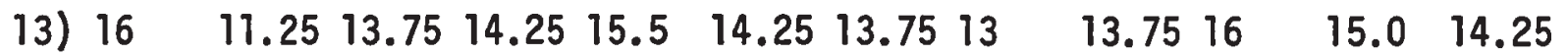

14) $\begin{array}{llllllllllll}16 & 15.75 & 15.5 & 16 & 16 & 16 & 16 & 16 & 16 & 16 & 16 & 16\end{array}$

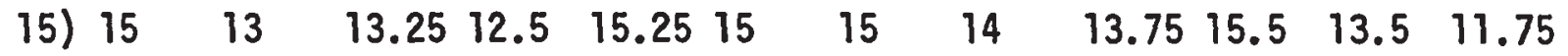

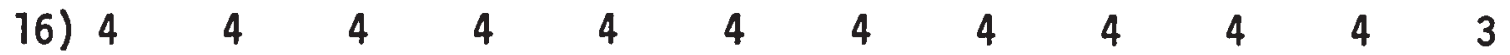

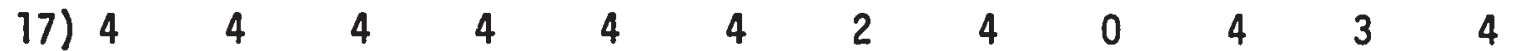

18) $4 \quad 4 \quad 4 \quad 4 \quad 4 \quad \begin{array}{llllllll} & 4 & 4 & 3 & 3 & 4 & 4 & 3\end{array}$

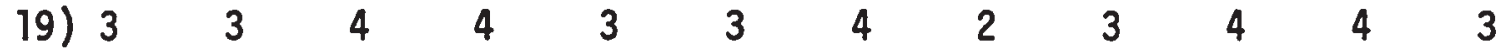

20) $\begin{array}{llllllllllll}12 & 12 & 12 & 14 & 13 & 12 & 12 & 12 & 12 & 14 & 10 & 11\end{array}$ 
TABLE 5

Raw Scores. Experiment II

( 3 sec. viewing time)

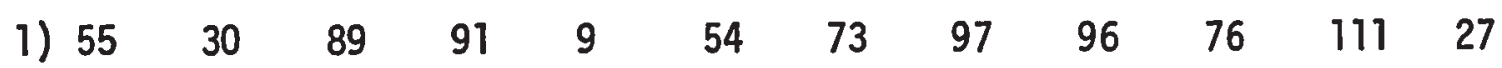

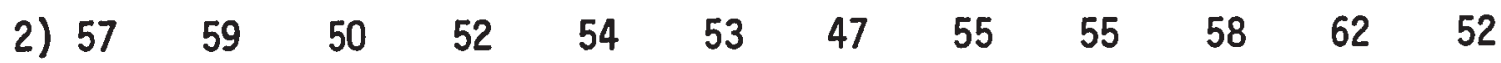

3) $\begin{array}{llllllllllll}1 & 1 & 1 & 1 & 1 & 1 & 2 & 2 & 2 & 2 & 2 & 2\end{array}$

4) $\begin{array}{llllllllllll}7 & 6 & 4 & 4 & 3 & 7 & 7 & 7 & 7 & 6 & 7 & 6\end{array}$

5) $\begin{array}{llllllllllll}128 & 85 & 66 & 68 & 87 & 80 & 90 & 63 & 75 & 94 & 94 & 75\end{array}$

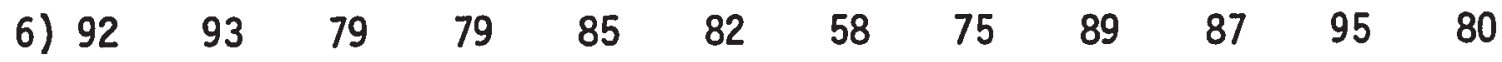

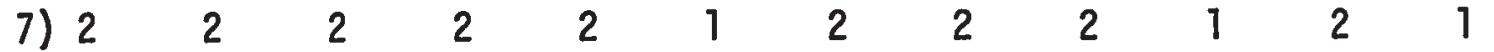

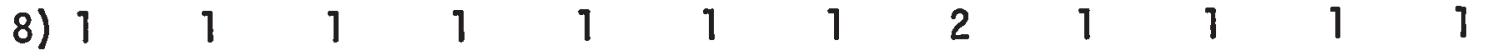

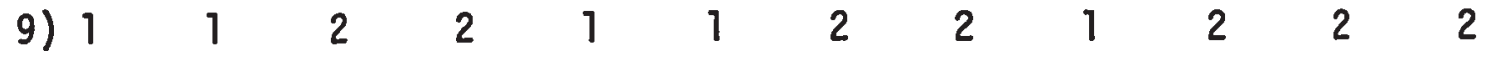

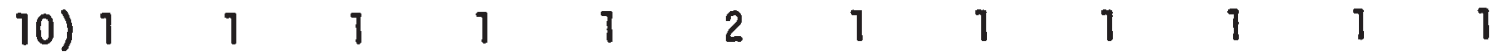

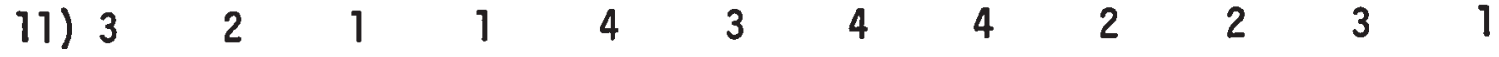

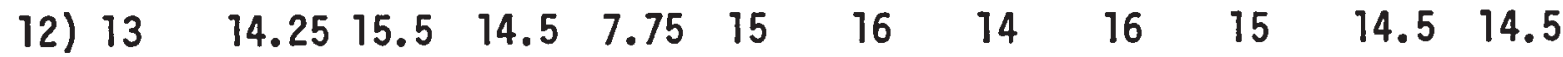

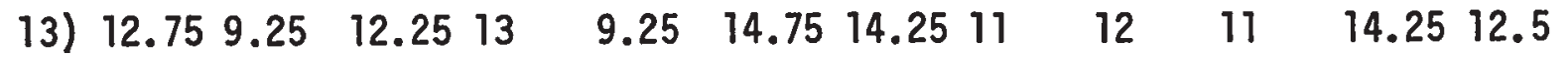

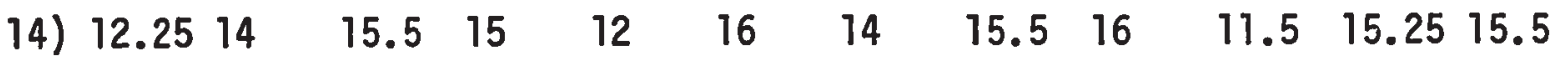

15) $11.5 \quad 10 \quad 12.75 \quad 13.5 \quad 9.25 \quad 13.75 \quad 11.25 \quad 13.75 \quad 12.259 .25 \quad 10.75 \quad 11.75$

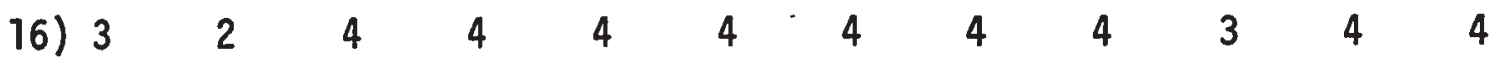

17) $\begin{array}{llllllllllll}3 & 2 & 4 & 3 & 3 & 3 & 3 & 2 & 4 & 2 & 3 & 4\end{array}$

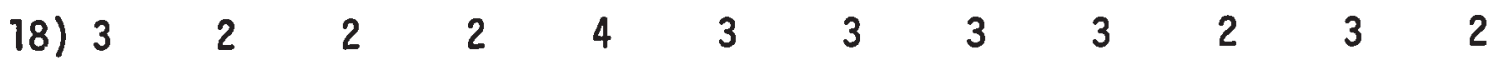

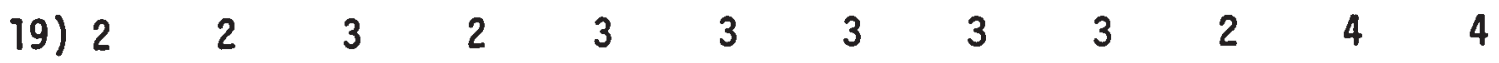

20) $\begin{array}{llllllllllll}12 & 12 & 14 & 12 & 12 & 10 & 10 & 11 & 12 & 11 & 14 & 10\end{array}$ 


\section{TABLE 6}

\section{Raw Scores. Experiment II}

( 3 sec. viewing time)

1) $\begin{array}{llllllllllll}15 & 50 & 62 & 14 & 65 & 13 & 18 & 25 & 45 & 35 & 38 & 34\end{array}$ 2) $\begin{array}{llllllllllll}19 & 21 & 22 & 20 & 21 & 22 & 22 & 24 & 20 & 20 & 23 & 20\end{array}$ 3) $\begin{array}{llllllllllll}1 & 1 & 1 & 1 & 1 & 1 & 2 & 2 & 2 & 2 & 2 & 2\end{array}$ 4) $7 \begin{array}{lllllllllll}7 & 5 & 7 & 4 & 7 & 6 & 7 & 7 & 7 & 7 & 7\end{array}$ 5) $\begin{array}{llllllllllll}105 & 66 & 65 & 96 & 50 & 66 & 73 & 108 & 64 & 74 & 118 & 75\end{array}$ 6) $\begin{array}{llllllllllll}64 & 81 & 78 & 91 & 94 & 79 & 67 & 90 & 63 & 95 & 96 & 90\end{array}$ 7) $\begin{array}{llllllllllll}1 & 1 & 1 & 1 & 1 & 1 & 1 & 2 & 1 & 1 & 1 & 1\end{array}$

8) $\begin{array}{llllllllllll}2 & 1 & 1 & 1 & 1 & 2 & 1 & 2 & 1 & 1 & 1 & 2\end{array}$

9) $\begin{array}{llllllllllll}1 & 2 & 2 & 2 & 2 & 1 & 2 & 2 & 2 & 2 & 2 & 1\end{array}$

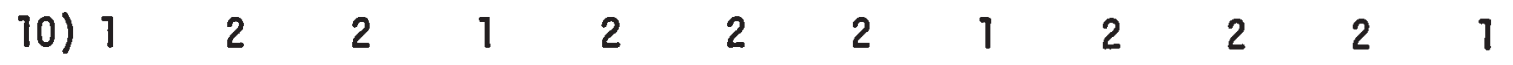

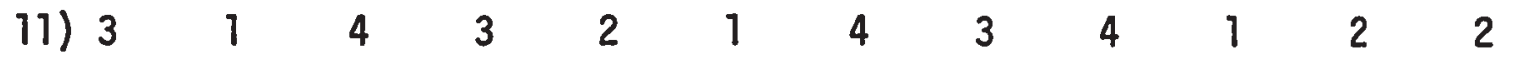

12) $\begin{array}{llllllllllll}16 & 16 & 16 & 16 & 16 & 16 & 16 & 16 & 15 & 16 & 16 & 16\end{array}$

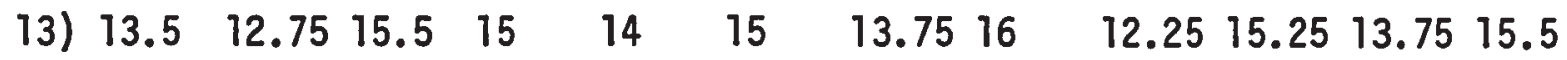

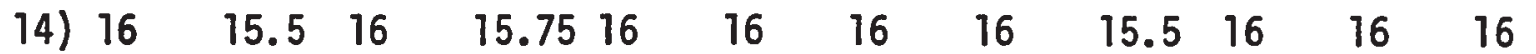

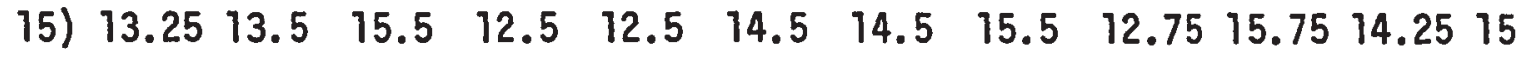

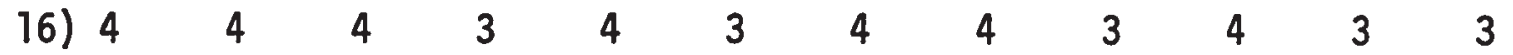

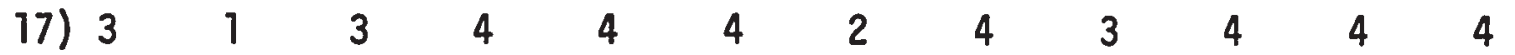

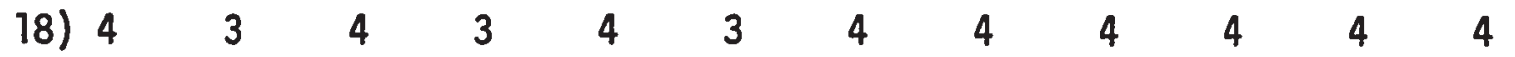

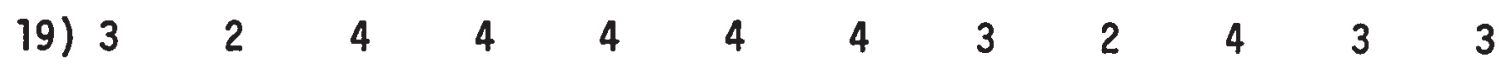
20) $\begin{array}{llllllllllll}14 & 13 & 10 & 12 & 13 & 11 & 12 & 11 & 11 & 15 & 16 & 14\end{array}$ 


\section{APPENDIX XII}

Analysis of educational levels

(Experiments I \& II) 
Comparisons of Young and 01der SS with Regard to Educational Levels (t-tests)

Table 1 (a) EXPERIMENT I

\begin{tabular}{lccc}
\hline & $Y, F$ & $A, M$ & $A, F$ \\
$Y, M$ & 0.0 & 2.17 & 1.74 \\
$Y, F$ & & $2.82 *$ & $2.56^{*}$ \\
$A, M$ & & & .71 \\
$*_{p<.05}$ & &
\end{tabular}

Table 1 (b)

EXPERIMENT II

\begin{tabular}{lrrr}
\hline & $Y, F$ & $A, M$ & $A, F$ \\
$Y, M$ & .57 & 1.45 & 1.52 \\
$Y, F$ & & .82 & .85 \\
& & & 0.0
\end{tabular}


Table 2 (a)

Correlations Between Educational Leve] and Other Variables (Experiment I)

\begin{tabular}{|c|c|c|c|c|c|c|c|c|c|}
\hline & 1 & 2 & 3 & 4 & 5 & 6 & 7 & 8 & 9 \\
\hline Education & $-580 *$ & 097 & .247 & .004 & .098 & .145 & -209 & .163 & $.431 *$ \\
\hline \multicolumn{10}{|l|}{$* p<.05$} \\
\hline \multicolumn{5}{|l|}{1 = Age } & \multicolumn{5}{|c|}{$6=$ Time-Recal1 } \\
\hline \multicolumn{5}{|l|}{$2=\operatorname{Sex}$} & \multicolumn{5}{|c|}{7 = Time-Recognition } \\
\hline \multicolumn{5}{|c|}{$3=$ Visua 1 Discrimination Task } & \multicolumn{5}{|c|}{$8=$ Recall } \\
\hline \multicolumn{5}{|l|}{$4=Q M I$} & \multicolumn{5}{|c|}{$9=$ Recognition } \\
\hline $5=Q W T$ & & & & & & & & & \\
\hline
\end{tabular}

Table 2 (b)

Correlation Between Education and Recognition Task Performance After the Effects of Age are Partialled Out

$$
R_{12.3}=\frac{.431-(.580)(.475)}{\sqrt{1-(.580)^{2}} \sqrt{1-(.475)^{2}}}=.217
$$




\section{Educational Levels}

Table 3 (a)

Number of Years in School (Experiment I)

\begin{tabular}{|c|c|c|c|c|}
\hline & \multicolumn{2}{|c|}{ Males } & \multicolumn{2}{|c|}{ Females } \\
\hline & $\bar{x}$ & s.d & $\bar{x}$ & s.d \\
\hline Young & 14.0 & 2.9 & 14.0 & 1.2 \\
\hline 01der & 10.0 & 2.9 & 11.2 & 2.2 \\
\hline
\end{tabular}

Table 3 (b)

Number of Years in School (Experiment II)

\begin{tabular}{cccccc}
\hline & \multicolumn{2}{c}{ Males } & \multicolumn{2}{c}{ Females } \\
& $\bar{x}$ & s.d & $\bar{X}$ & s.d \\
Young & 12.3 & 1.2 & 12.1 & 1.6 \\
Older & 11.6 & 1.9 & 11.6 & 1.8
\end{tabular}




\section{APPENDIX XIII}

Methodological Details (Experiments I and II) 
Since description of the procedure was somewhat abbreviated, further details are presented below. Instructions were given to the Ss before each block of 10 slides. In the recall condition, Ss were instructed to observe the stimulus patterns and then to place checkmarks in those respective squares of the answer sheets, where stimulus patterns were blacked in (see pp. 21, 22). Taperecorded instructions were given to the $\underline{S} s$, i.e., with immediate recall, the $\underline{S}$ were told to "GOAHEAD" immediately after stimulus slide offset whereas with delayed recall, the $\underline{S}$ were instructed to "WAIT" (5 sec.) and then asked to "GO AHEAD". The procedure with recognition tasks was identical except that the response slide was presented either immediately after stimulus slide offset or after a $5 \mathrm{sec}$. delay. In addition, response sheets contained not $4 \times 4$ matrices but rather 6 empty squares which corresponded to the matrix squares presented on the response slides.

Conditions were partially counterbalanced so that $\underline{S} s$ received one of 4 orders of task presentation, i.e., recall or recognition task first and delay or no delay condition first. The $\underline{S}$ were not presented with random permutations of the 4 tasks. For example, $\underline{S}$ could have had the following order of stimulus blocks:

a) recall, delay b) recall, no delay c) recognition, delay d) recognition, no delay but could not have had the following order of stimulus blocks: a) recall, delay b) recognition, no delay c) recognition, delay d) recall, no delay.

Raw scores used in data analysis consisted of: a) recall taskthe number of cells remembered per matrix up to a maximum of 16 (per subject per condition) b) recognition task-the number of correctly 
recognized patterns up to a maximum of 4 (per subject per condition) c) self-paced viewing time-number of seconds required by the individual to view the stimulus patterns. Numerical values presented in the body of the thesis refer to the forementioned measures and the reader should infer from the context which of these mean values are being discussed at any given time. 